\title{
Direct cyclopropanation of quinolinium zwitterionic thiolates via dearomative reactions
}

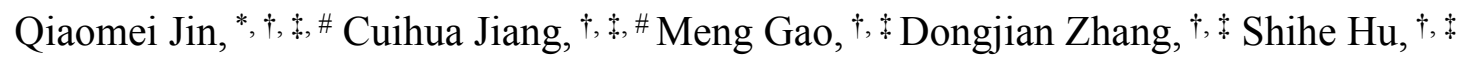
Jian Zhang ${ }^{*}, \dagger,+$

${ }^{\dagger}$ Affiliated Hospital of Integrated Traditional Chinese and Western Medicine, Nanjing University of Chinese Medicine, Nanjing 210028, Jiangsu, China

Laboratories of Translational Medicine, Jiangsu Province Academy of Traditional Chinese Medicine, Nanjing 210028, Jiangsu, China

E-mail:jiqmxy@163.com,zjwonderful@hotmail.com 


\section{Table of Contents}

1. X-ray structure of derivative 3a ------------------------------------------------S3

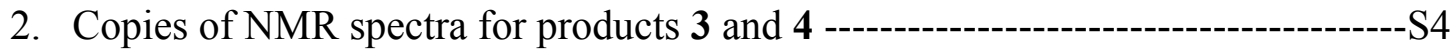




\section{X-ray structure of derivative 3 a (displacement ellipsoids are drawn at the $50 \%$ probability level).}

The structure of 3a (CCDC 2080623) recrystalized from ethyl acetate/petroleum ether. X-ray data was collected at $296 \mathrm{~K}$ on a Bruker APEX-II CCD detector diffractometer.

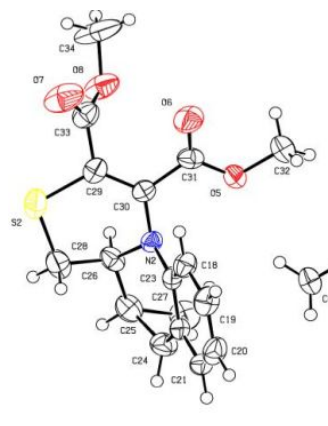

Bond precision:

Cell :

Temperature:

Volume
Space group
Hall group
Moiety formula
Sum formula
Mr

$\mathrm{Dx}, \mathrm{g} \mathrm{cm}-3$

$\mathrm{Z}$

$\mathrm{Mu}(\mathrm{mm}-1)$

F000

F000'

$\mathrm{h}, \mathrm{k}, \mathrm{lmax}$

Nref

Tmin, Tmax

Tmin'

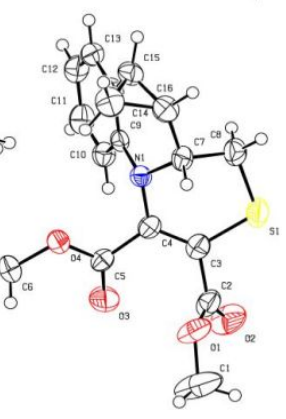

$\mathrm{C}-\mathrm{C}=0.0070 \mathrm{~A}$

$\mathrm{a}=12.5285(13)$

alpha $=90$

$296 \mathrm{~K}$

\section{Calculated} $3205.9(6)$

P $\mathrm{n}$ a 21

P $2 \mathrm{C}-2 \mathrm{n}$

$\begin{array}{lllllll}\mathrm{C} 17 & \mathrm{H} 17 & \mathrm{~N} & \mathrm{O} 4 & \mathrm{~S}\end{array}$

C17 H17 N O4 S

331.38

1.373

8

0.222

1392.0

1393.65

$14,13,26$

5644 [ 2901]

$0.946,0.957$

0.944<smiles>C#CC(=O)C1=C(C(=O)OC)N2c3ccccc3[C@@H]3C[C@H]3[C@H]2CS1</smiles>

and<smiles>COC(=O)C1=C(C(=O)OC)N2c3ccccc3[C@@H]3CC3[C@@H]2CS1</smiles>

$3 a$

Wavelength $=0.71073$

$\mathrm{b}=11.3981$ (12)

beta $=90$

$\mathrm{C}=22.450$ (2)

gamma $=90$

\footnotetext{
Correction method= Not given

Data completeness $=1.70 / 0.87$

Theta $(\max )=24.993$

$R$ (reflections $)=0.0383(3871)$

WR2 (reflections $)=0.0976(4938)$

$S=0.936$

Npar $=419$
} 


\section{Copies of NMR spectra for products 3}

3a

${ }^{1} \mathrm{H} \mathrm{NMR}\left(400 \mathrm{MHz}, \mathrm{CDCl}_{3}\right)$

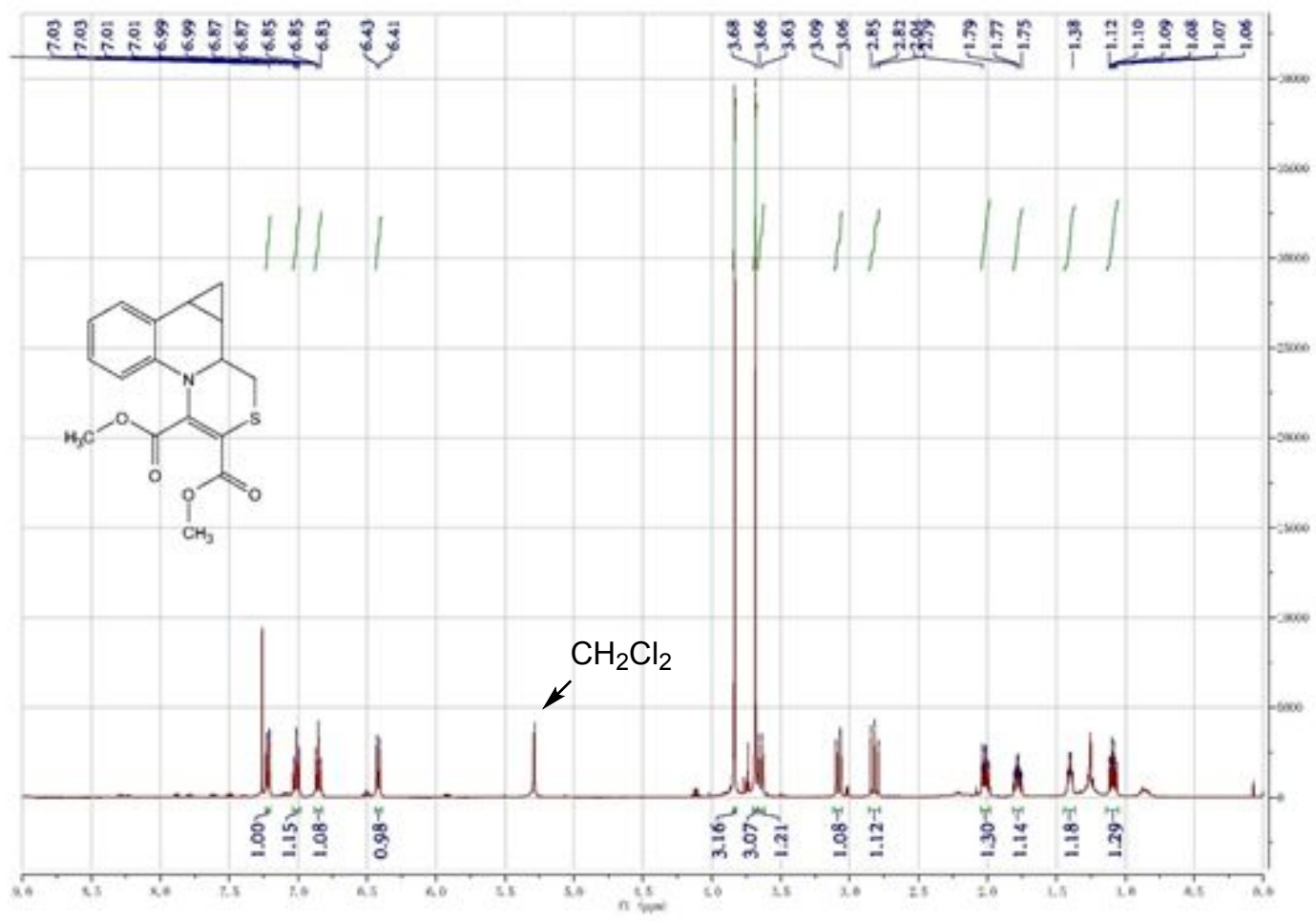

${ }^{13} \mathrm{C}\left\{{ }^{1} \mathrm{H}\right\}$ NMR $\left(100 \mathrm{MHz}, \mathrm{CDCl}_{3}\right)$

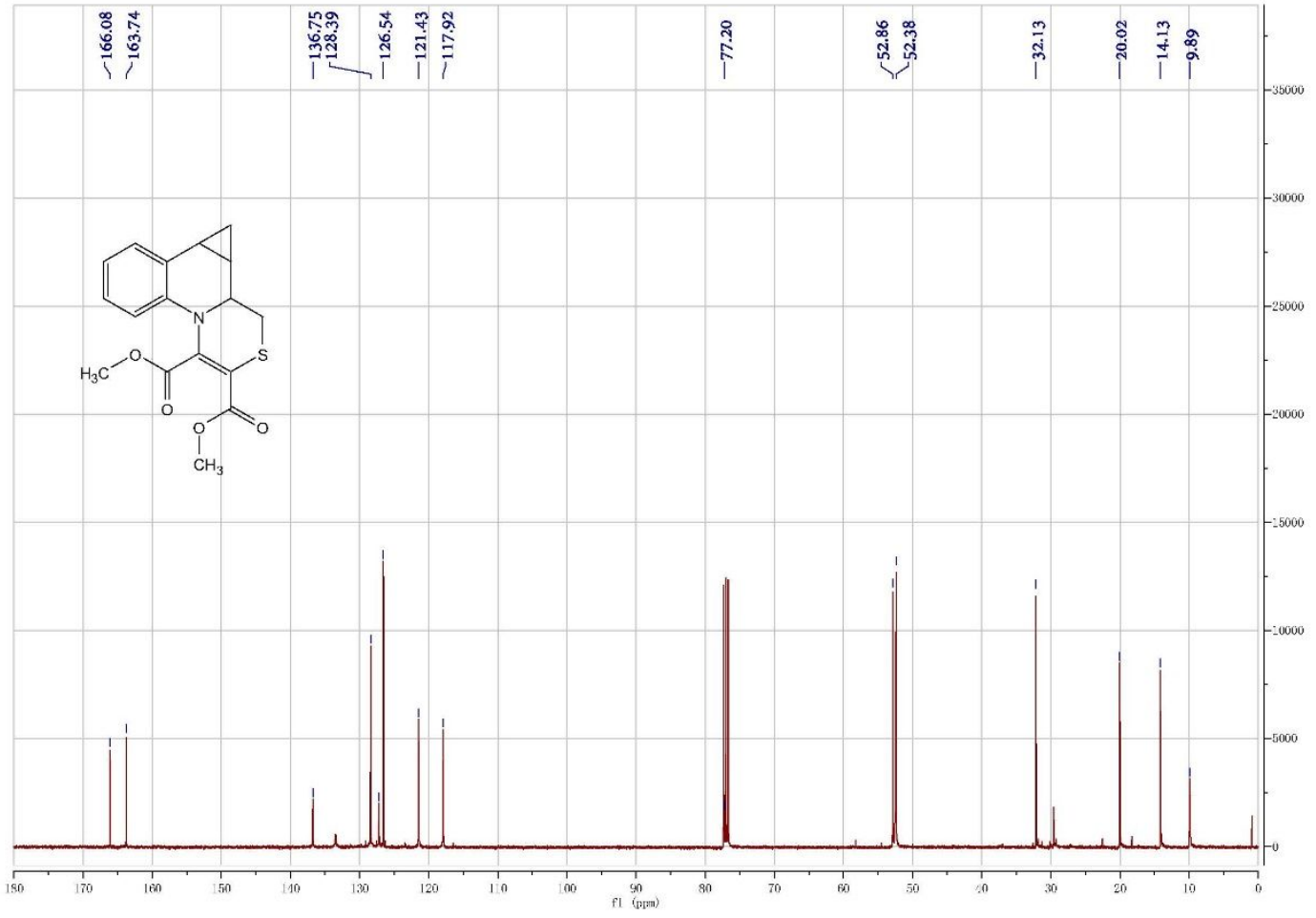


4a

${ }^{1} \mathrm{H}$ NMR (400 MHz, $\mathrm{CDCl}_{3}$ )

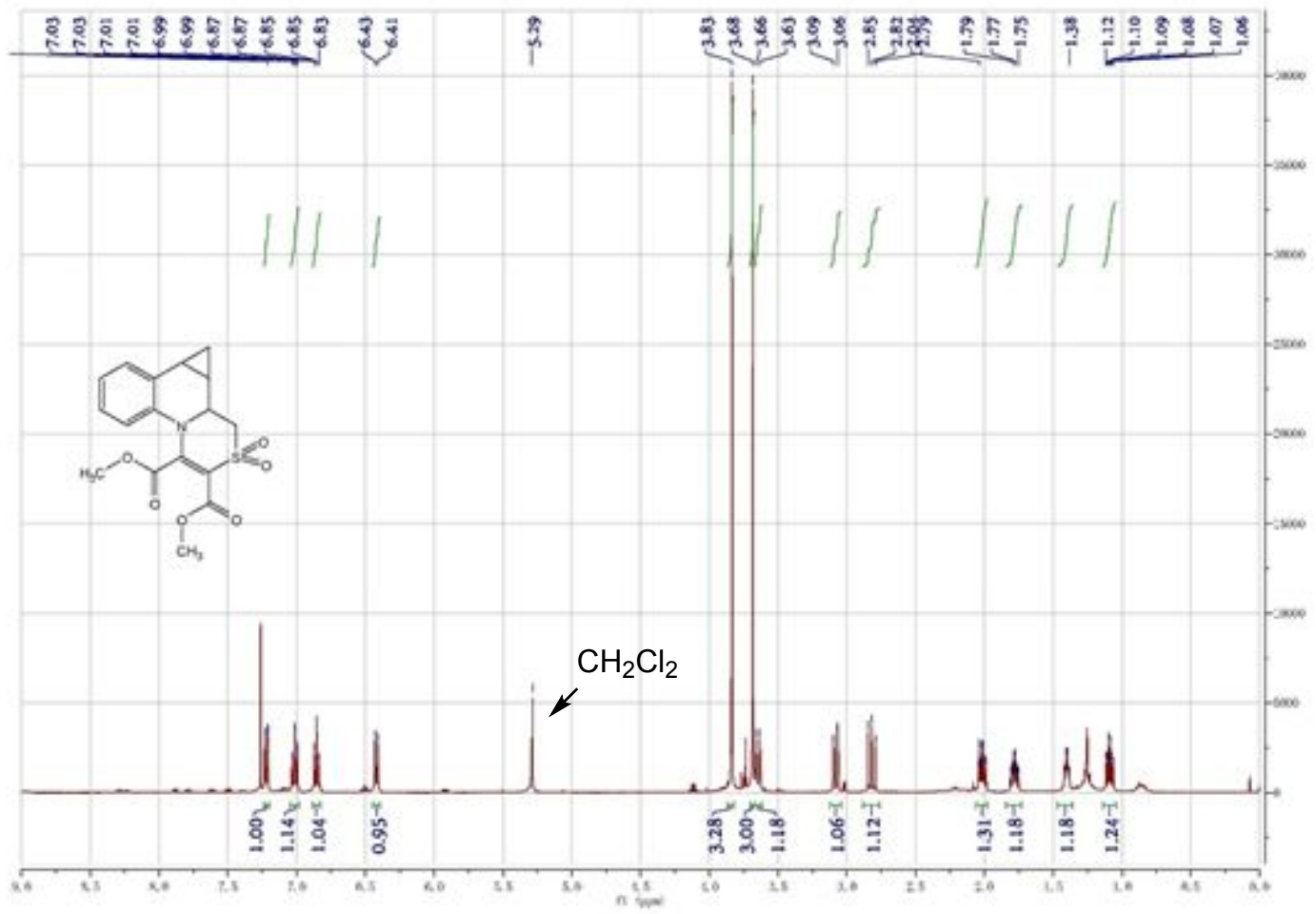

${ }^{13} \mathrm{C}\left\{{ }^{1} \mathrm{H}\right\} \mathrm{NMR}\left(100 \mathrm{MHz}, \mathrm{CDCl}_{3}\right)$

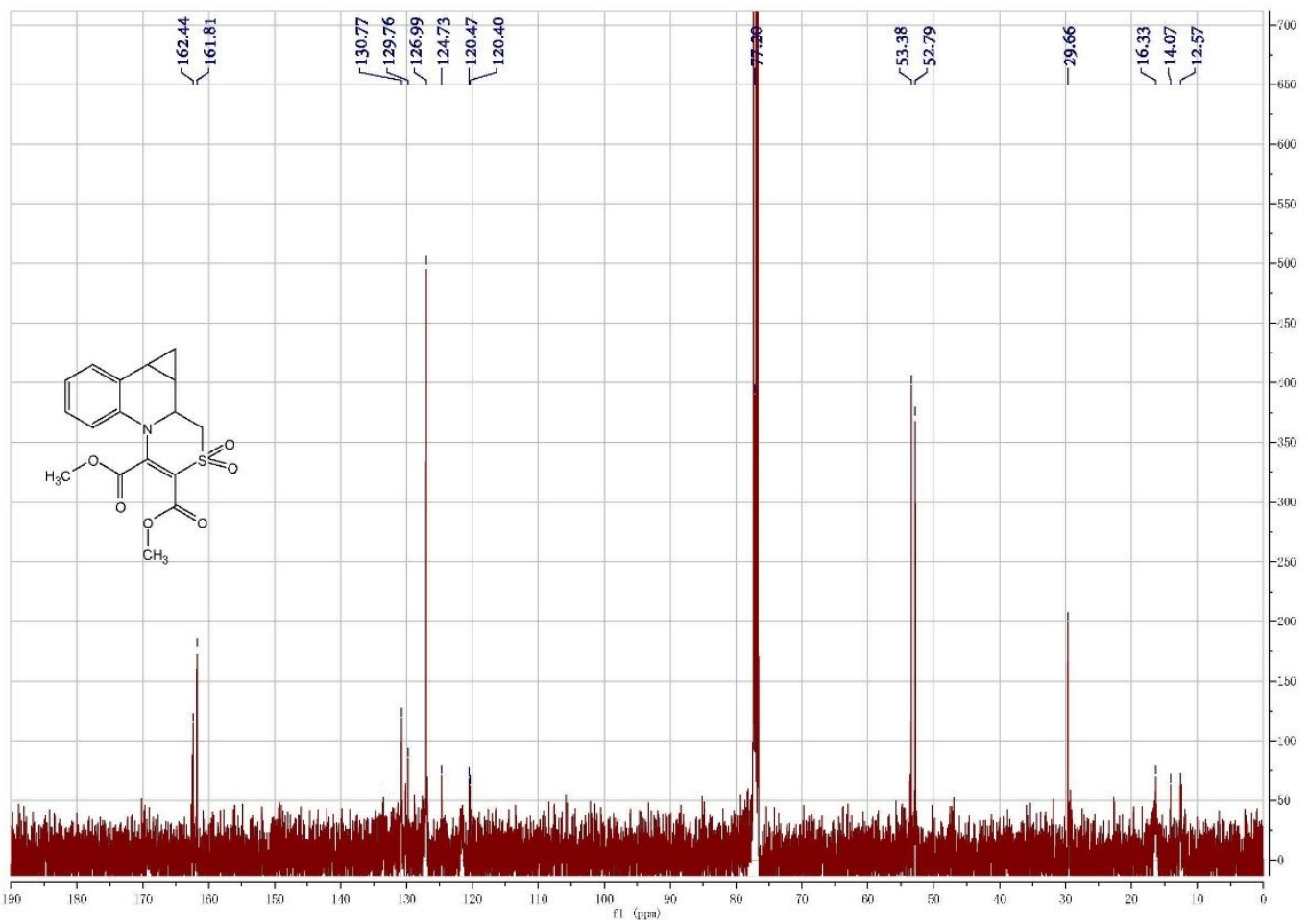

4b 
${ }^{1} \mathrm{H}$ NMR (400 MHz, $\mathrm{CDCl}_{3}$ )

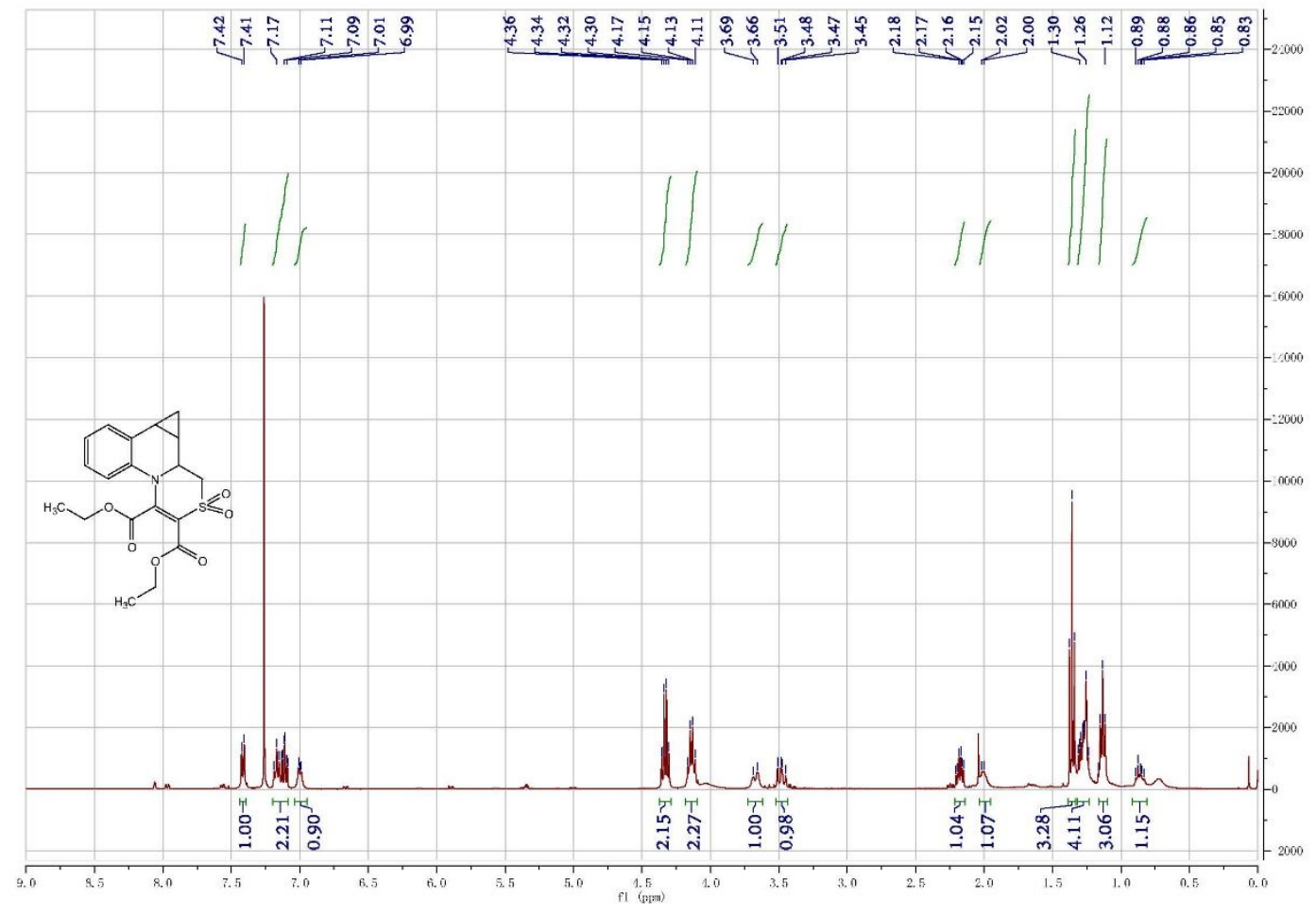

${ }^{13} \mathrm{C}\left\{{ }^{1} \mathrm{H}\right\}$ NMR $\left(100 \mathrm{MHz}, \mathrm{CDCl}_{3}\right)$

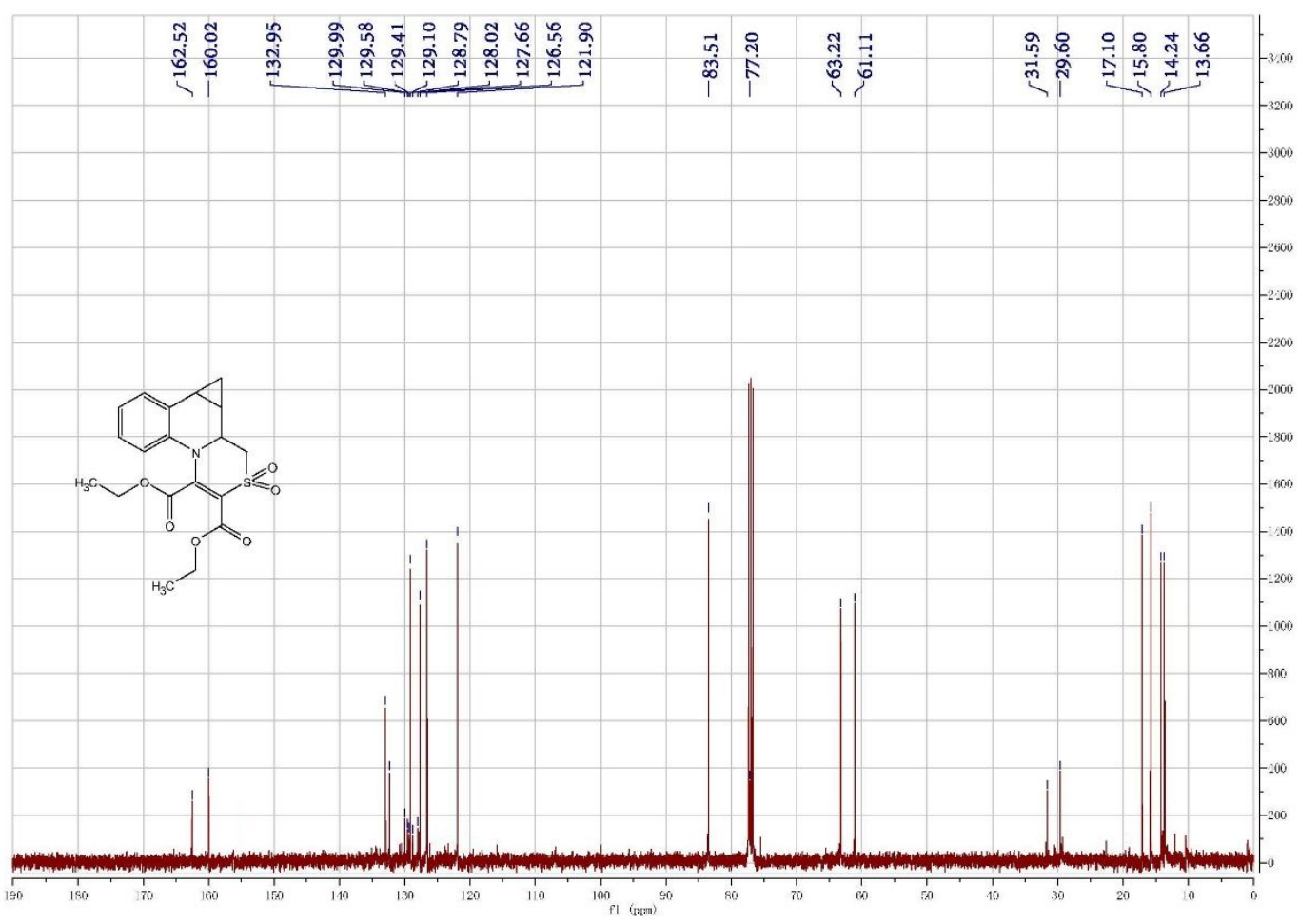

4c 
${ }^{1} \mathrm{H}$ NMR (400 MHz, $\left.\mathrm{CDCl}_{3}\right)$

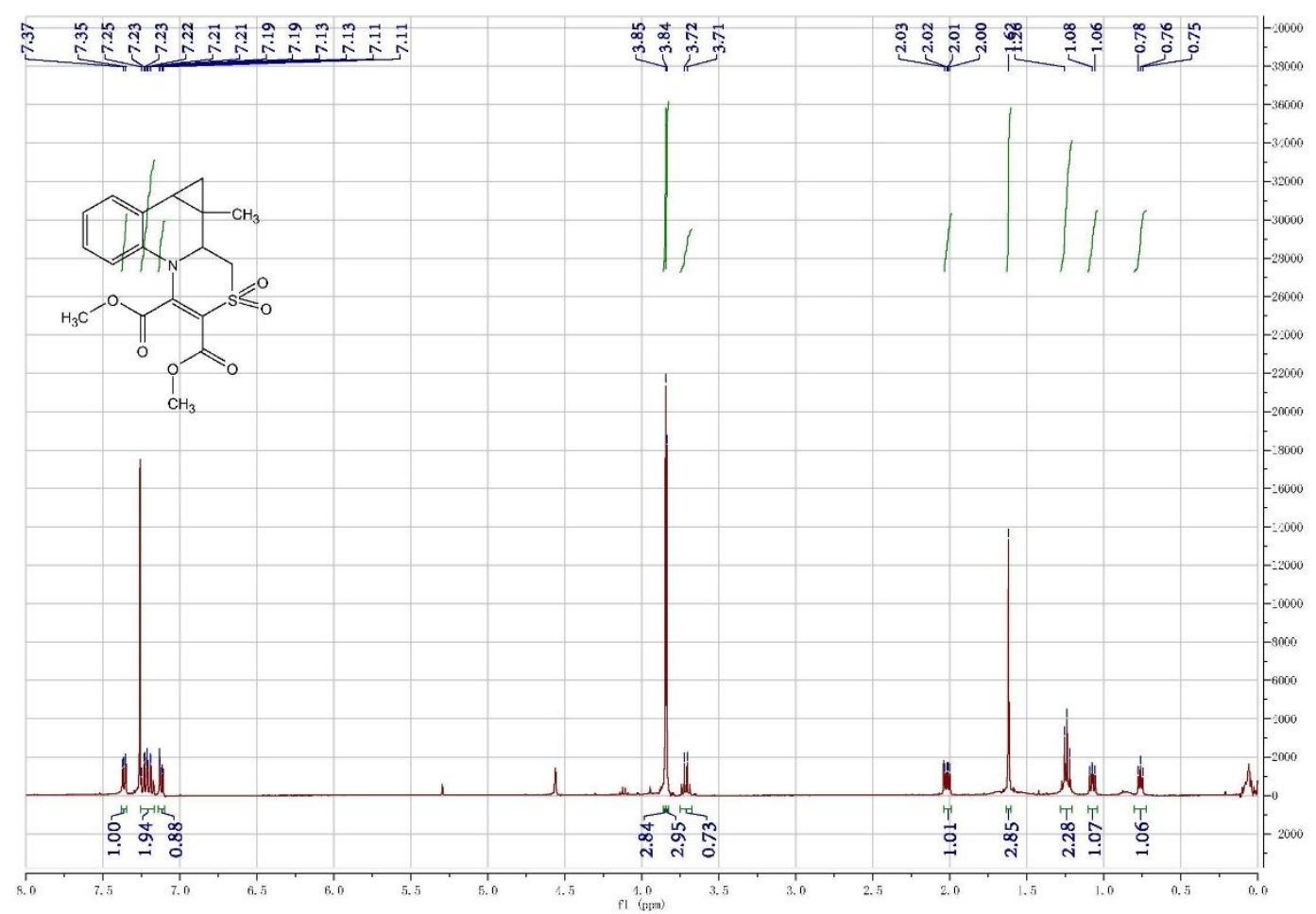

${ }^{13} \mathrm{C}\left\{{ }^{1} \mathrm{H}\right\} \mathrm{NMR}\left(100 \mathrm{MHz}, \mathrm{CDCl}_{3}\right)$

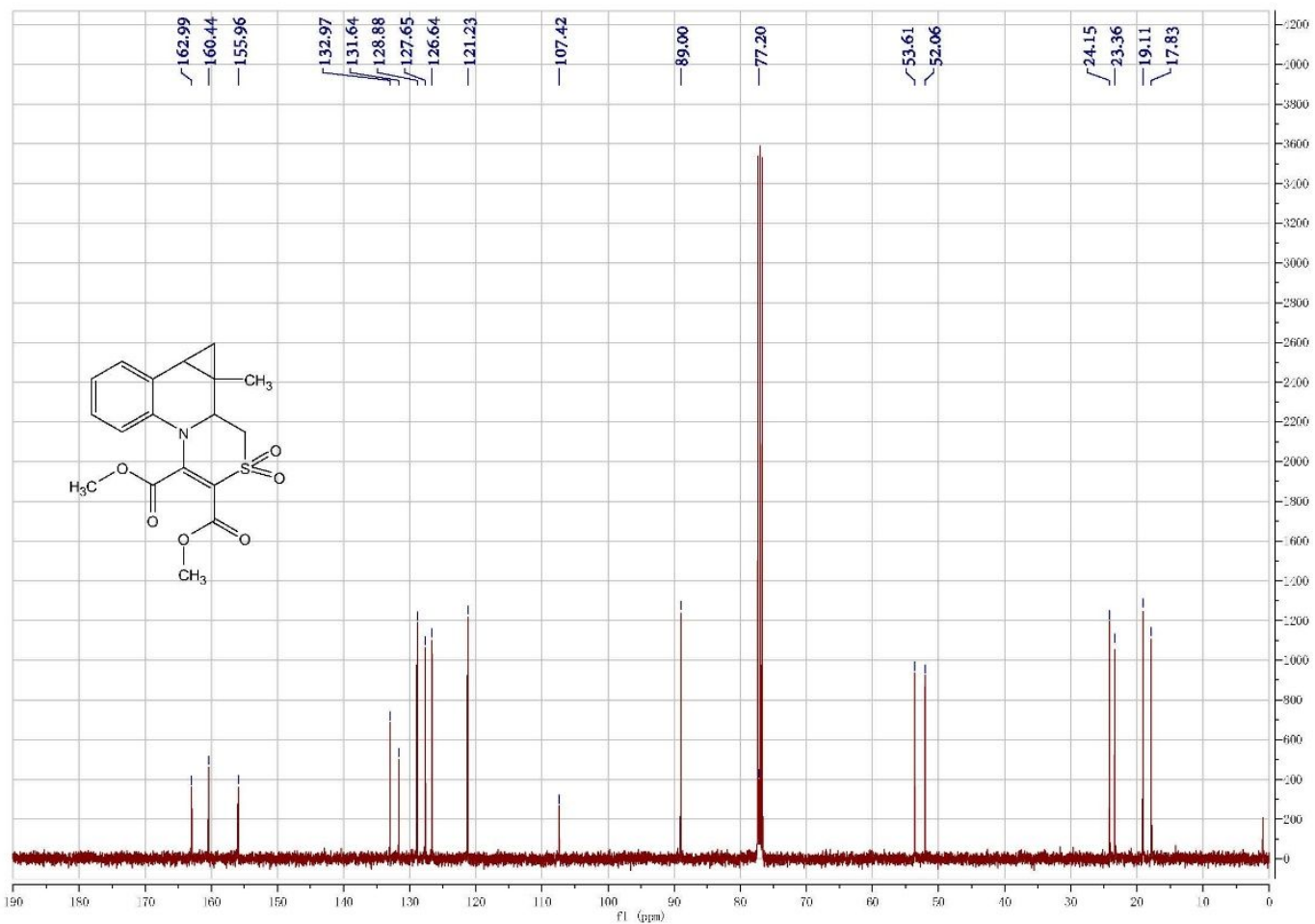

4d 
${ }^{1} \mathrm{H}$ NMR (400 MHz, $\left.\mathrm{CDCl}_{3}\right)$

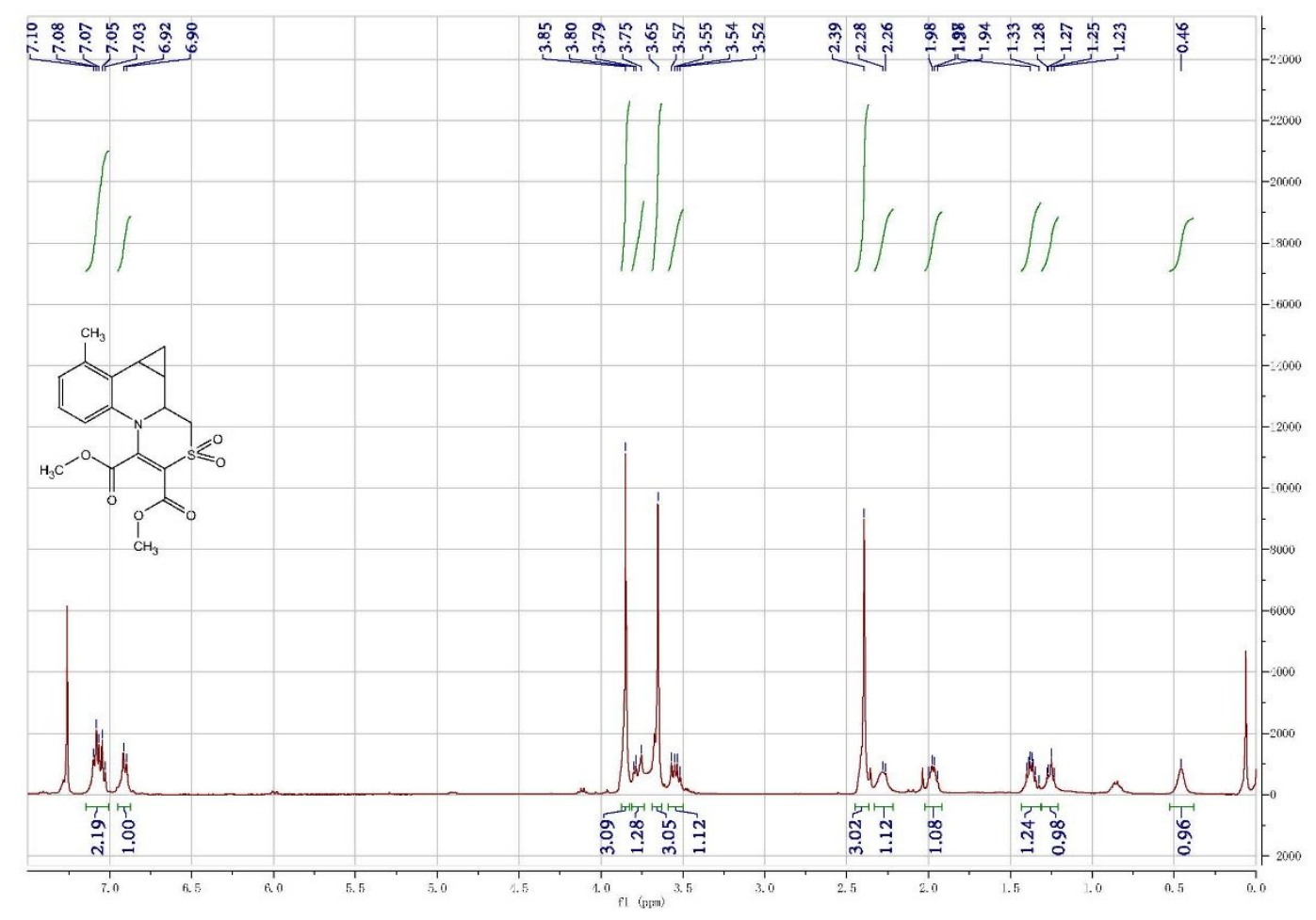

${ }^{13} \mathrm{C}\left\{{ }^{1} \mathrm{H}\right\} \mathrm{NMR}\left(100 \mathrm{MHz}, \mathrm{CDCl}_{3}\right)$

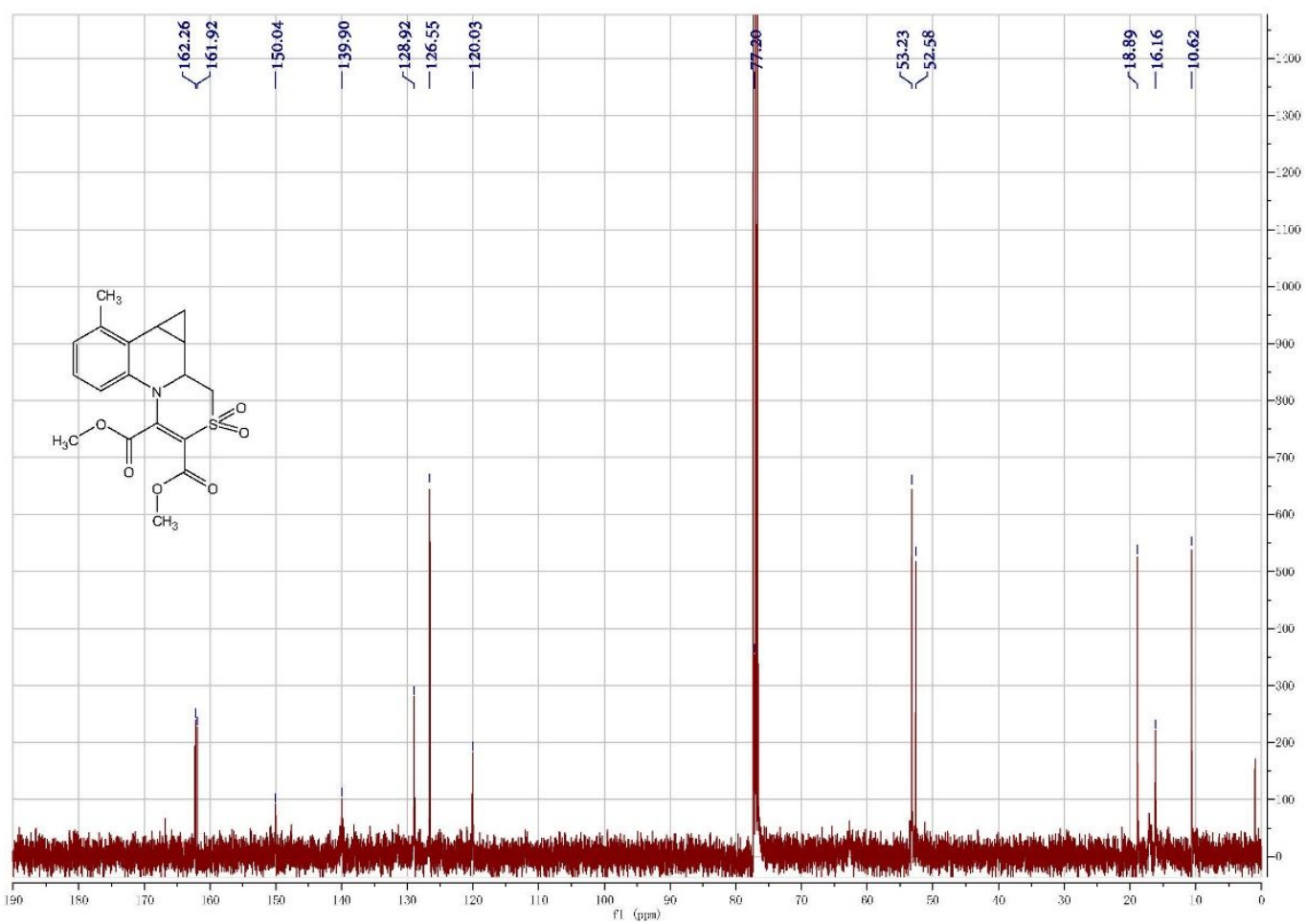

$4 e$ 
${ }^{1} \mathrm{H}$ NMR (400 MHz, $\mathrm{CDCl}_{3}$ )

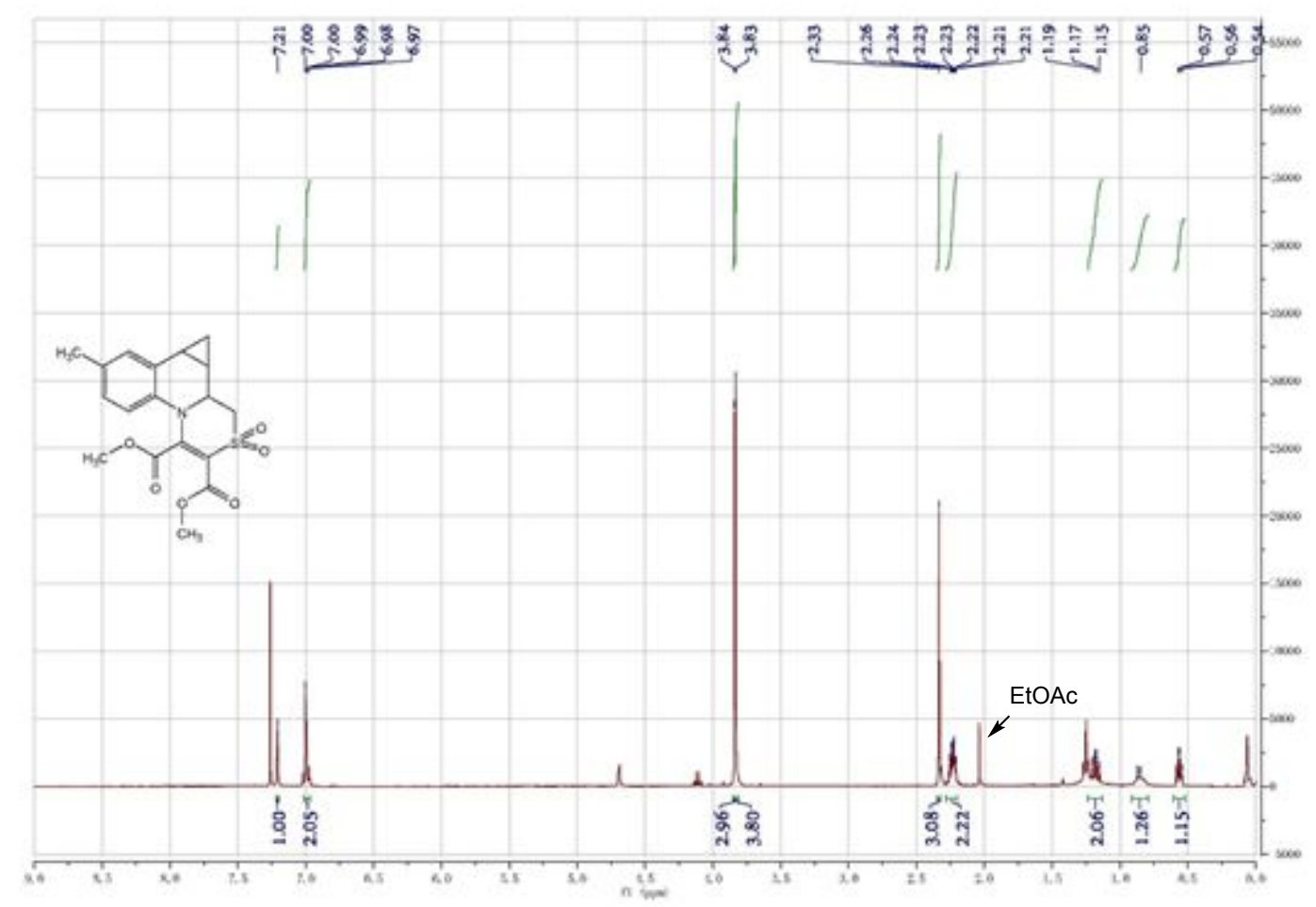

${ }^{13} \mathrm{C}\left\{{ }^{1} \mathrm{H}\right\}$ NMR $\left(100 \mathrm{MHz}, \mathrm{CDCl}_{3}\right)$

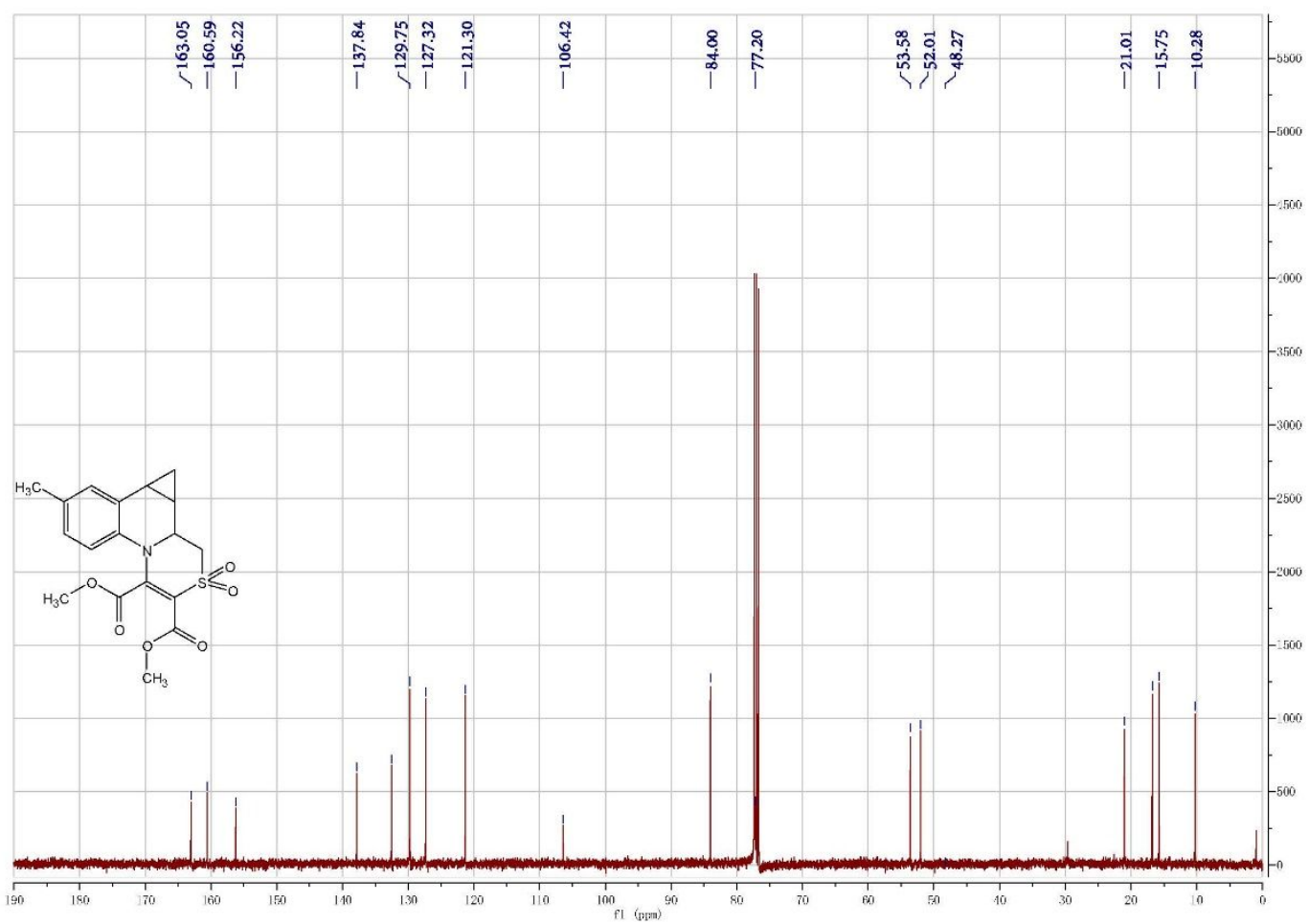

4f 
${ }^{1} \mathrm{H}$ NMR (400 MHz, DMSO- $d_{6}$ )

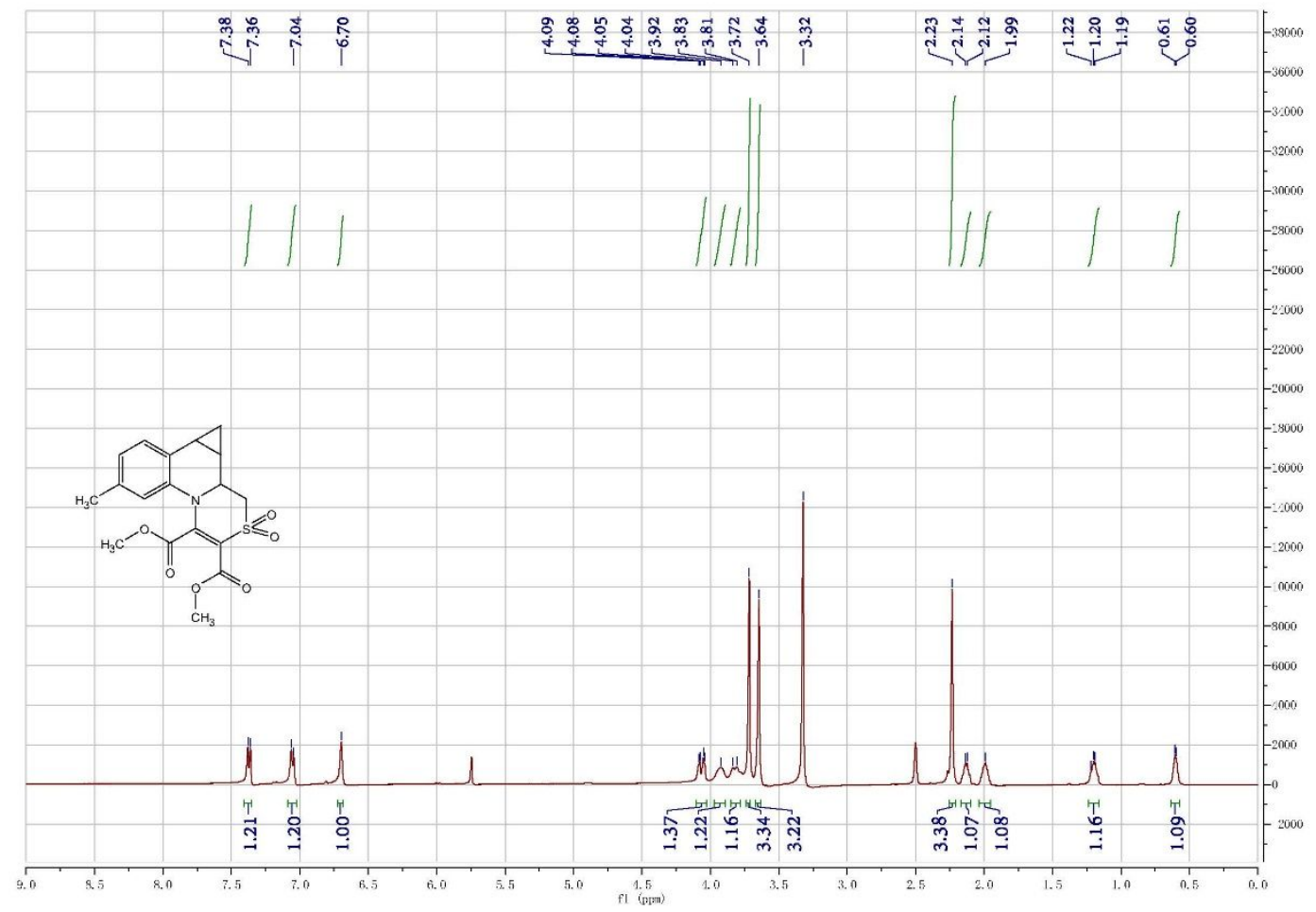

${ }^{13} \mathrm{C}\left\{{ }^{1} \mathrm{H}\right\}$ NMR (100 MHz, DMSO- $\left.d_{6}\right)$

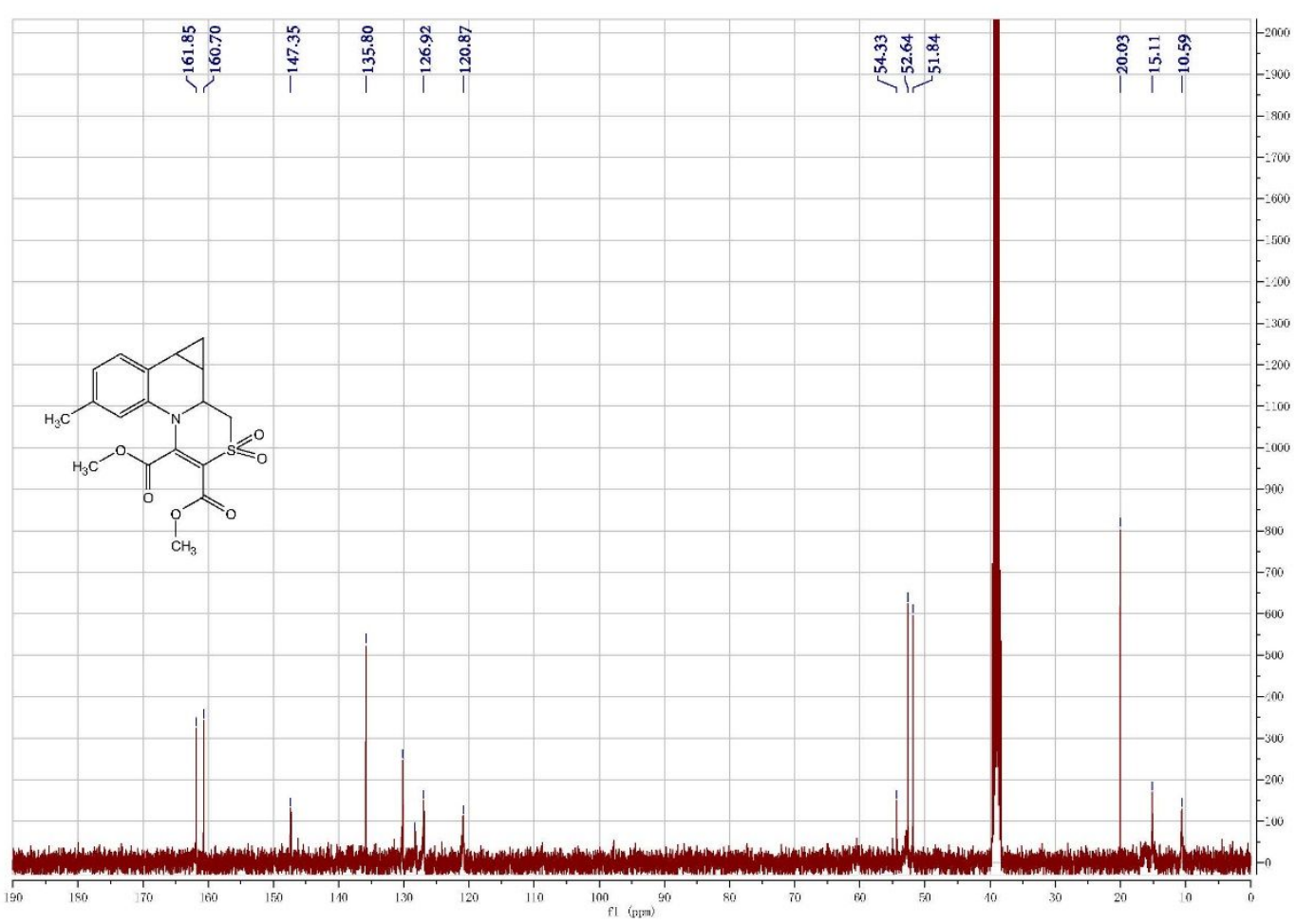

4h 
${ }^{1} \mathrm{H}$ NMR (400 MHz, DMSO- $d_{6}$ )

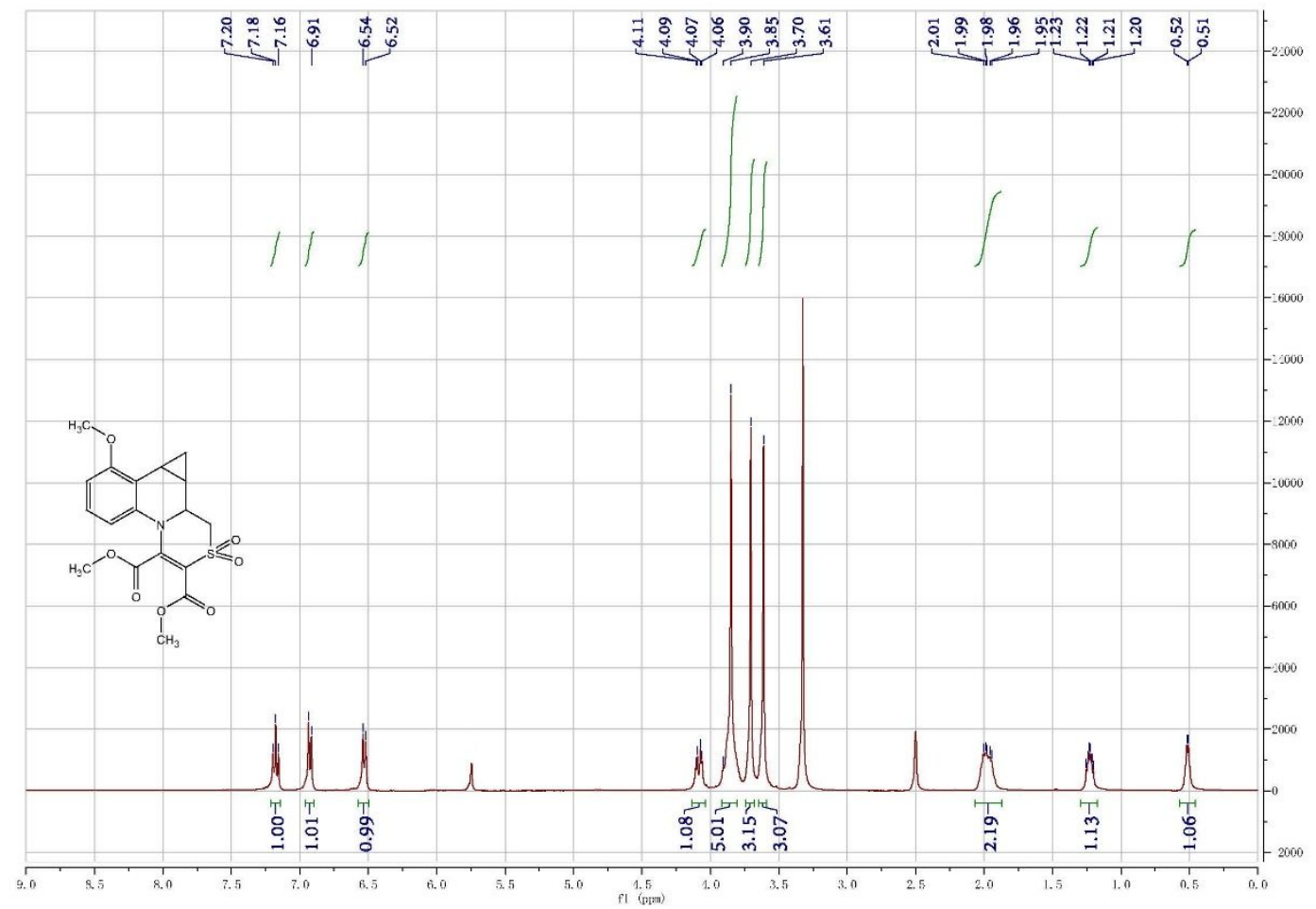

${ }^{13} \mathrm{C}\left\{{ }^{1} \mathrm{H}\right\}$ NMR (100 MHz, DMSO- $\left.d_{6}\right)$

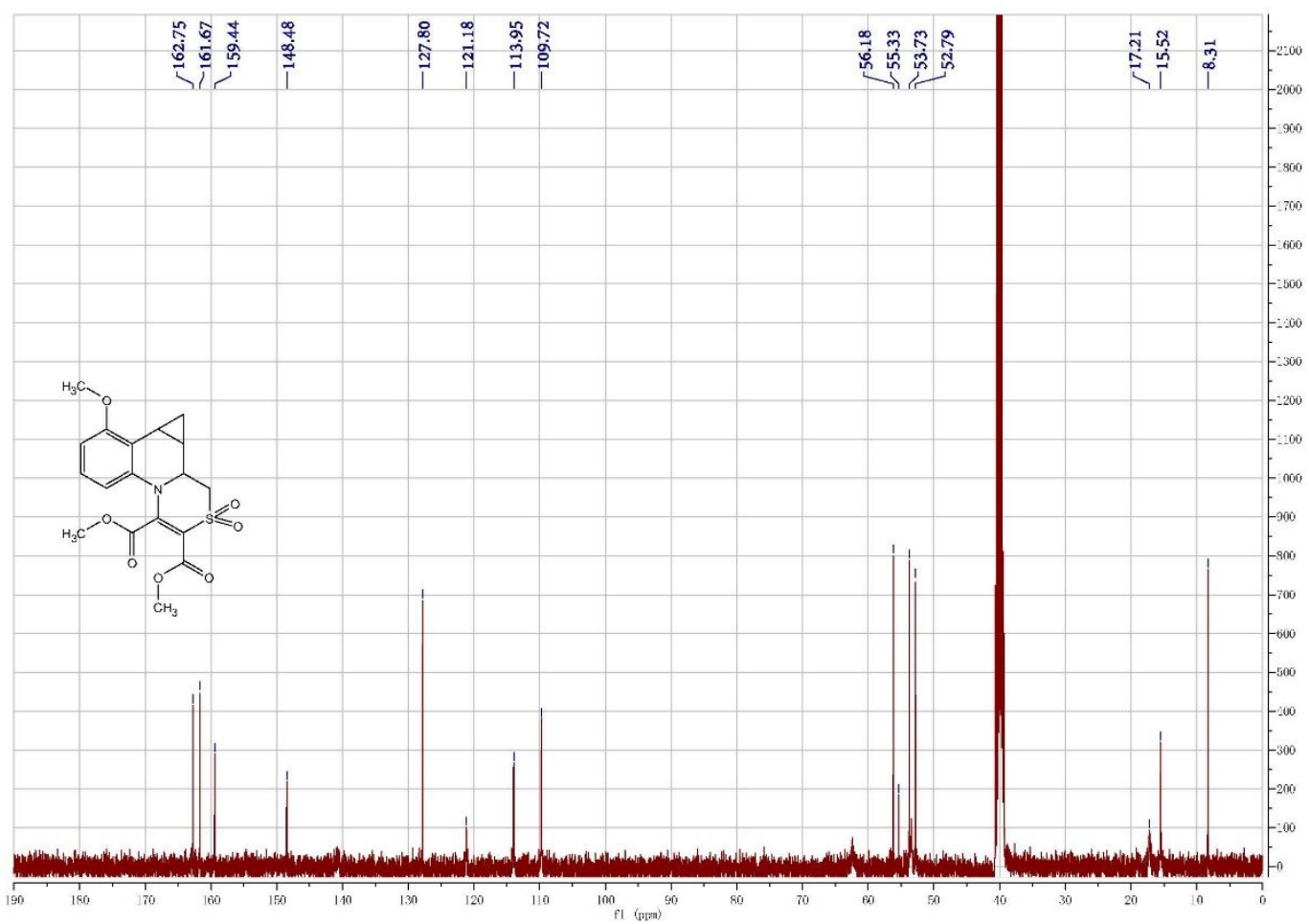


${ }^{1} \mathrm{H} \mathrm{NMR}\left(400 \mathrm{MHz}, \mathrm{CDCl}_{3}\right)$

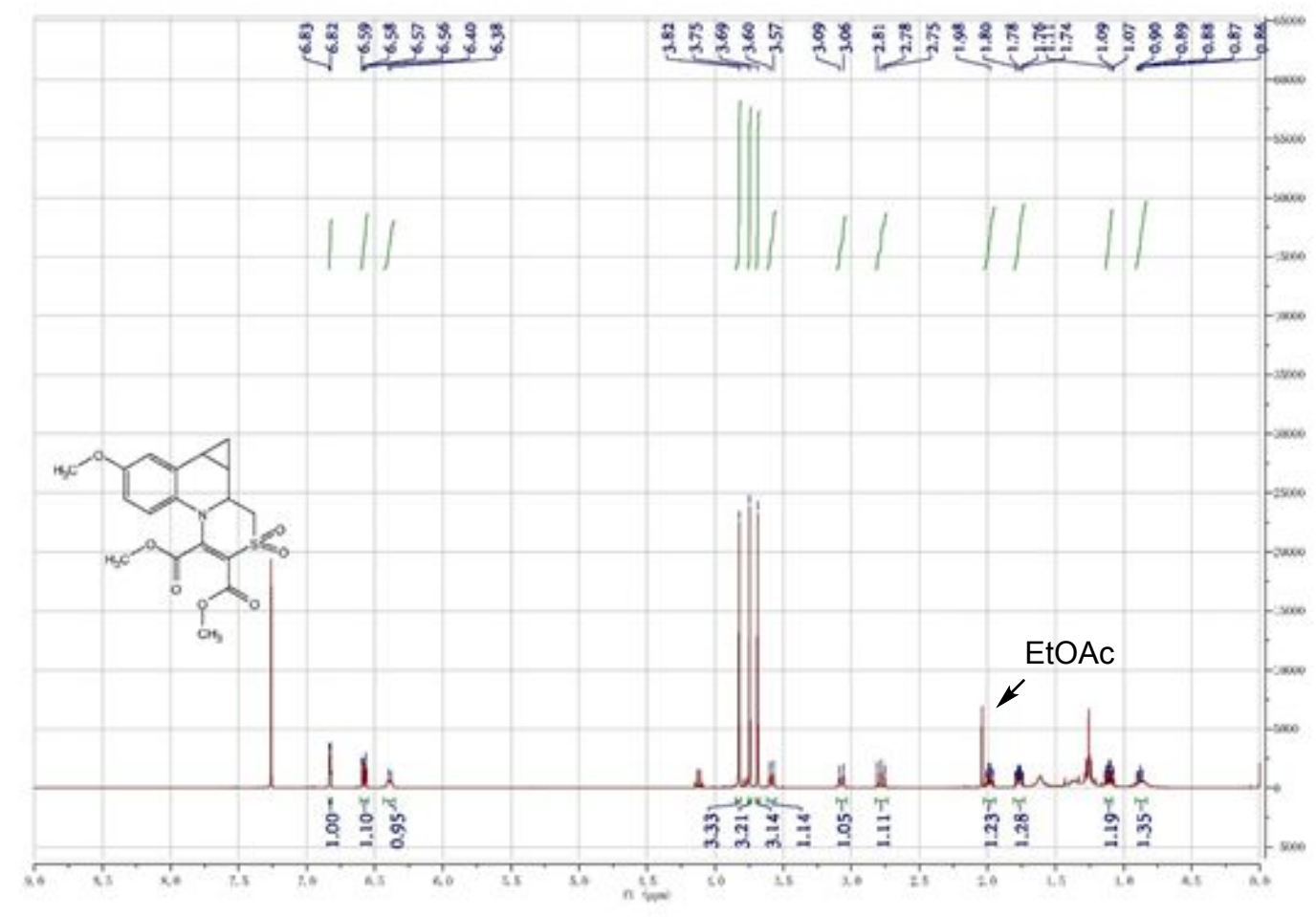

${ }^{13} \mathrm{C}\left\{{ }^{1} \mathrm{H}\right\}$ NMR $\left(100 \mathrm{MHz}, \mathrm{CDCl}_{3}\right)$

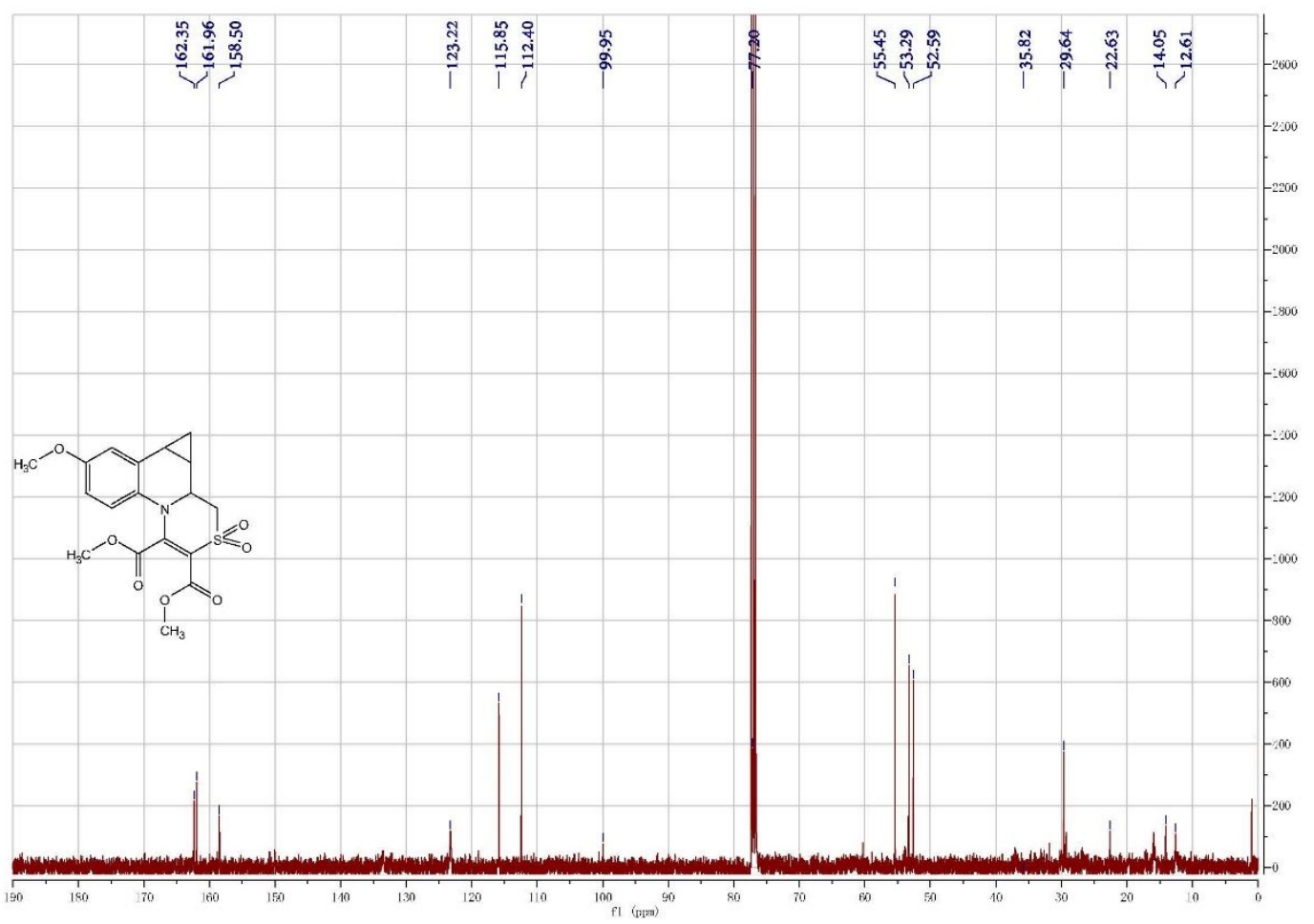


${ }^{1} \mathrm{H} \mathrm{NMR}\left(400 \mathrm{MHz}, \mathrm{CDCl}_{3}\right)$

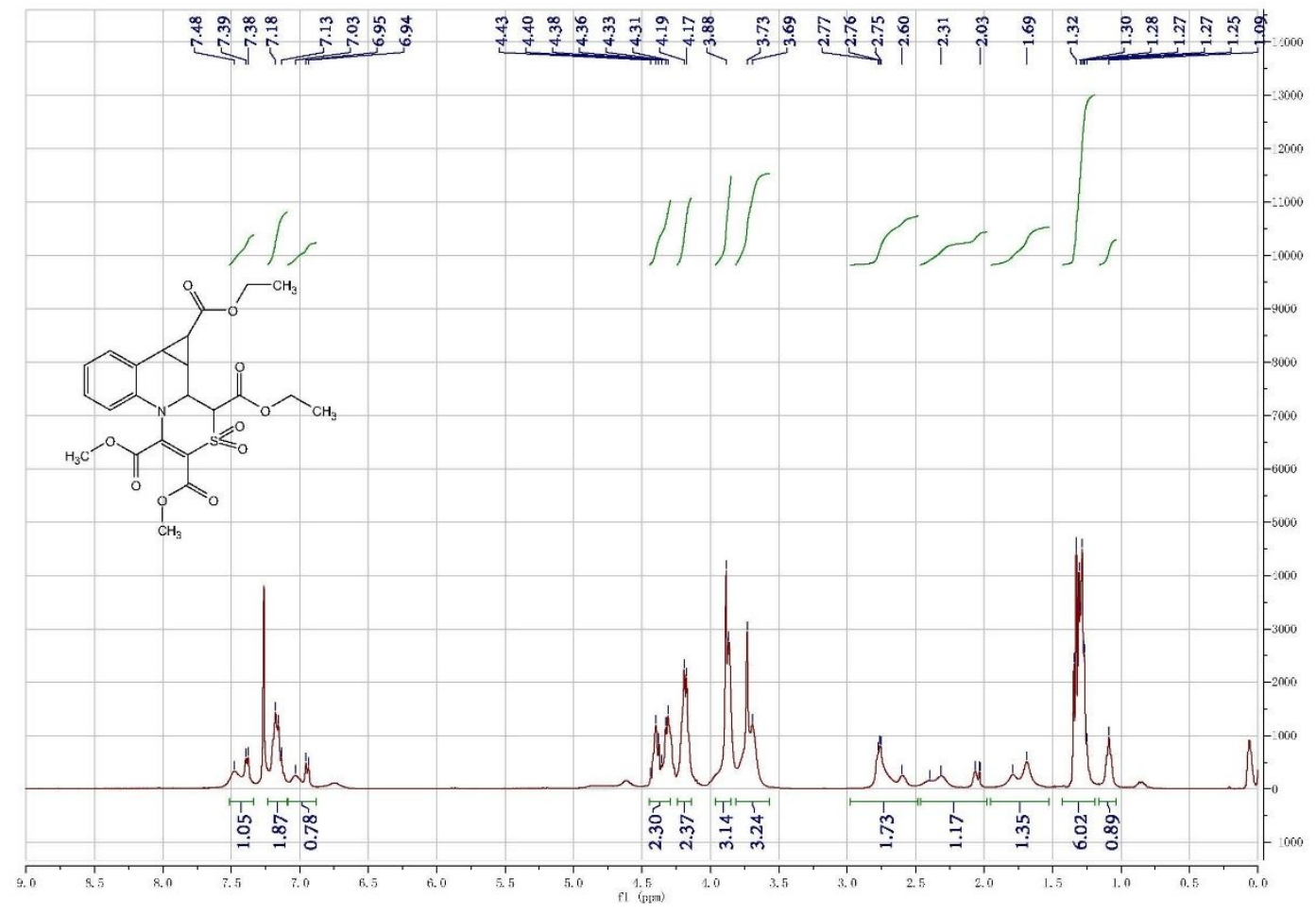

${ }^{13} \mathrm{C}\left\{{ }^{1} \mathrm{H}\right\}$ NMR $\left(100 \mathrm{MHz}, \mathrm{CDCl}_{3}\right)$

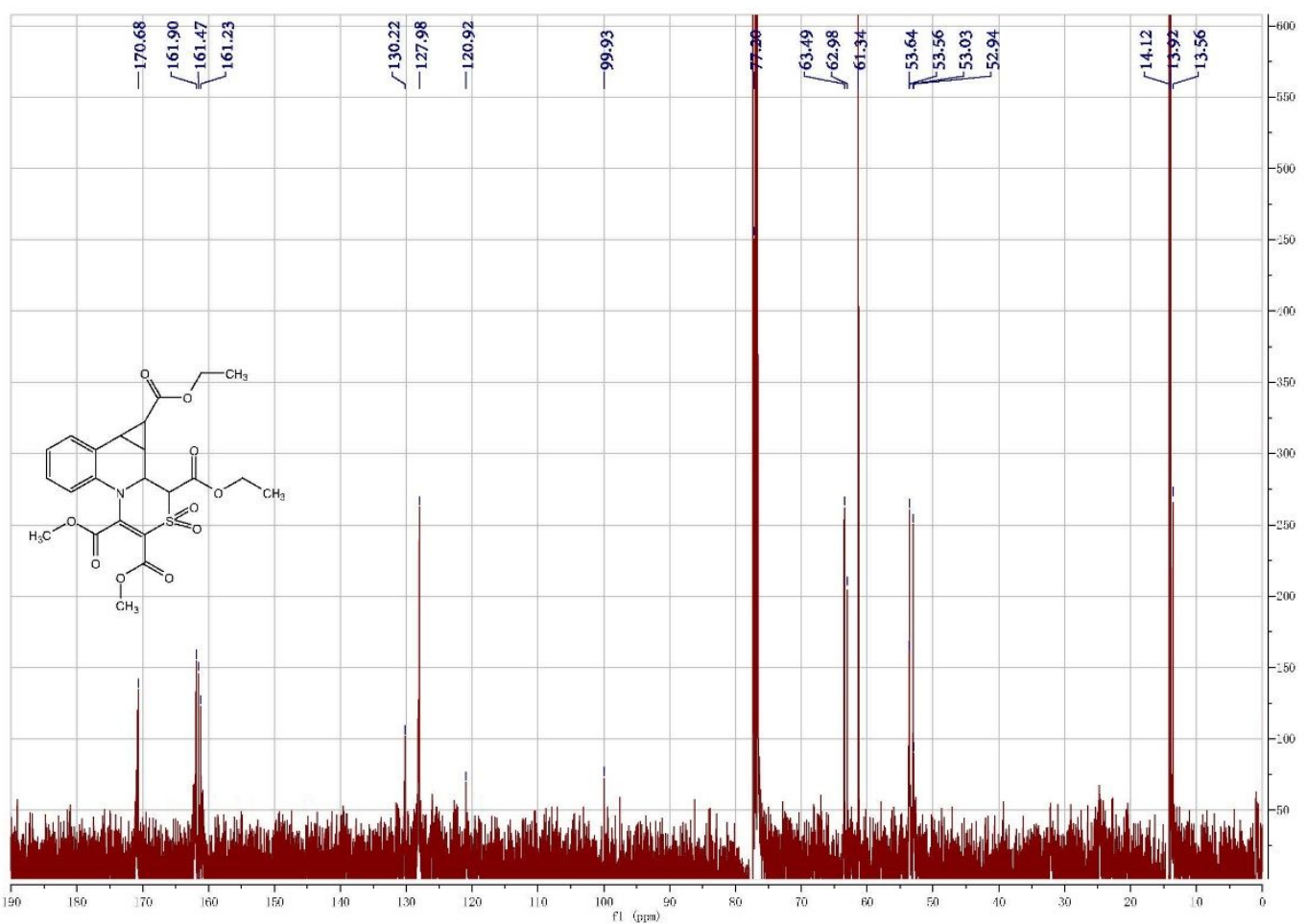

$4 k$ 
${ }^{1} \mathrm{H}$ NMR (400 MHz, $\mathrm{CDCl}_{3}$ )

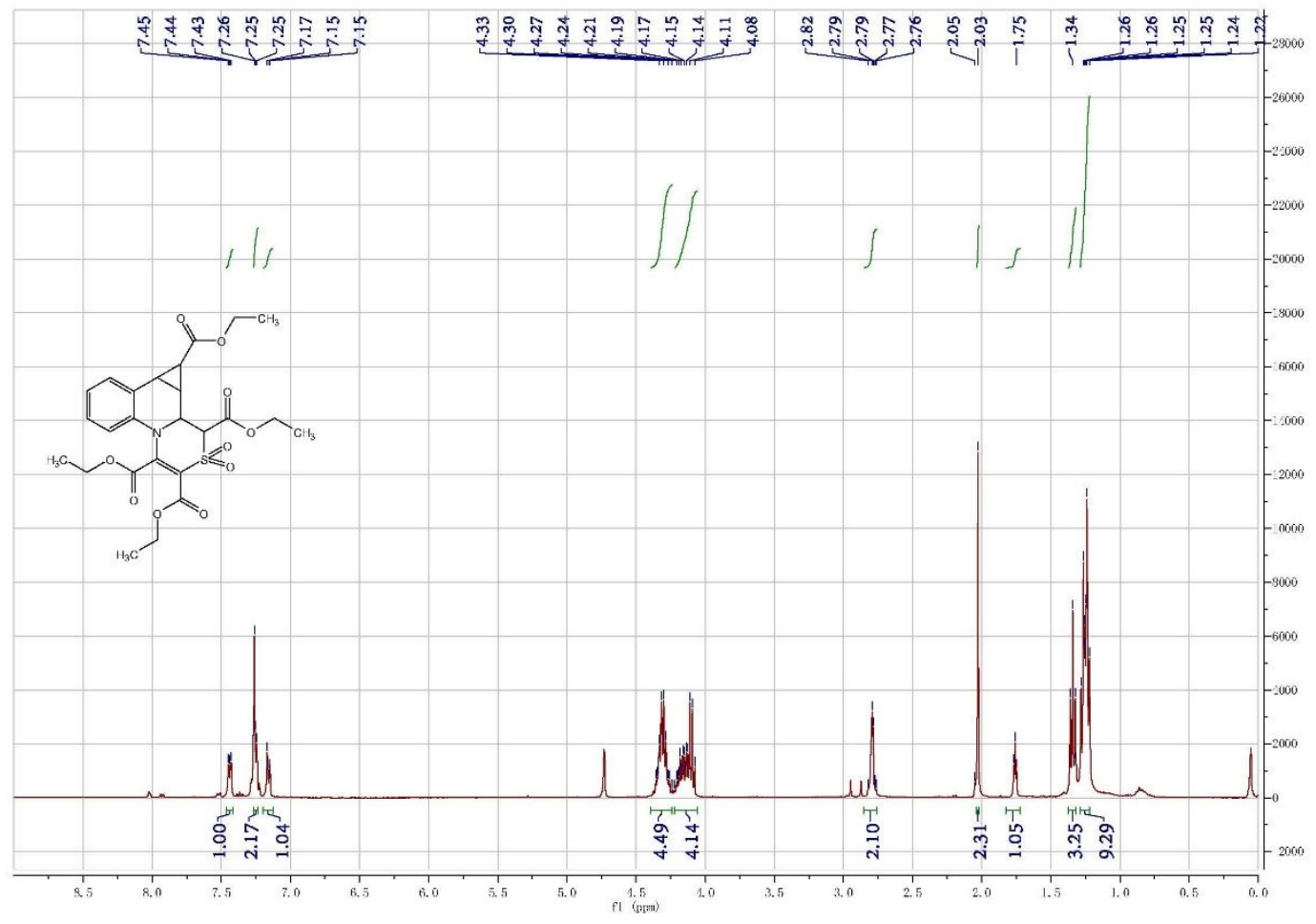

${ }^{13} \mathrm{C}\left\{{ }^{1} \mathrm{H}\right\}$ NMR $\left(100 \mathrm{MHz}, \mathrm{CDCl}_{3}\right)$

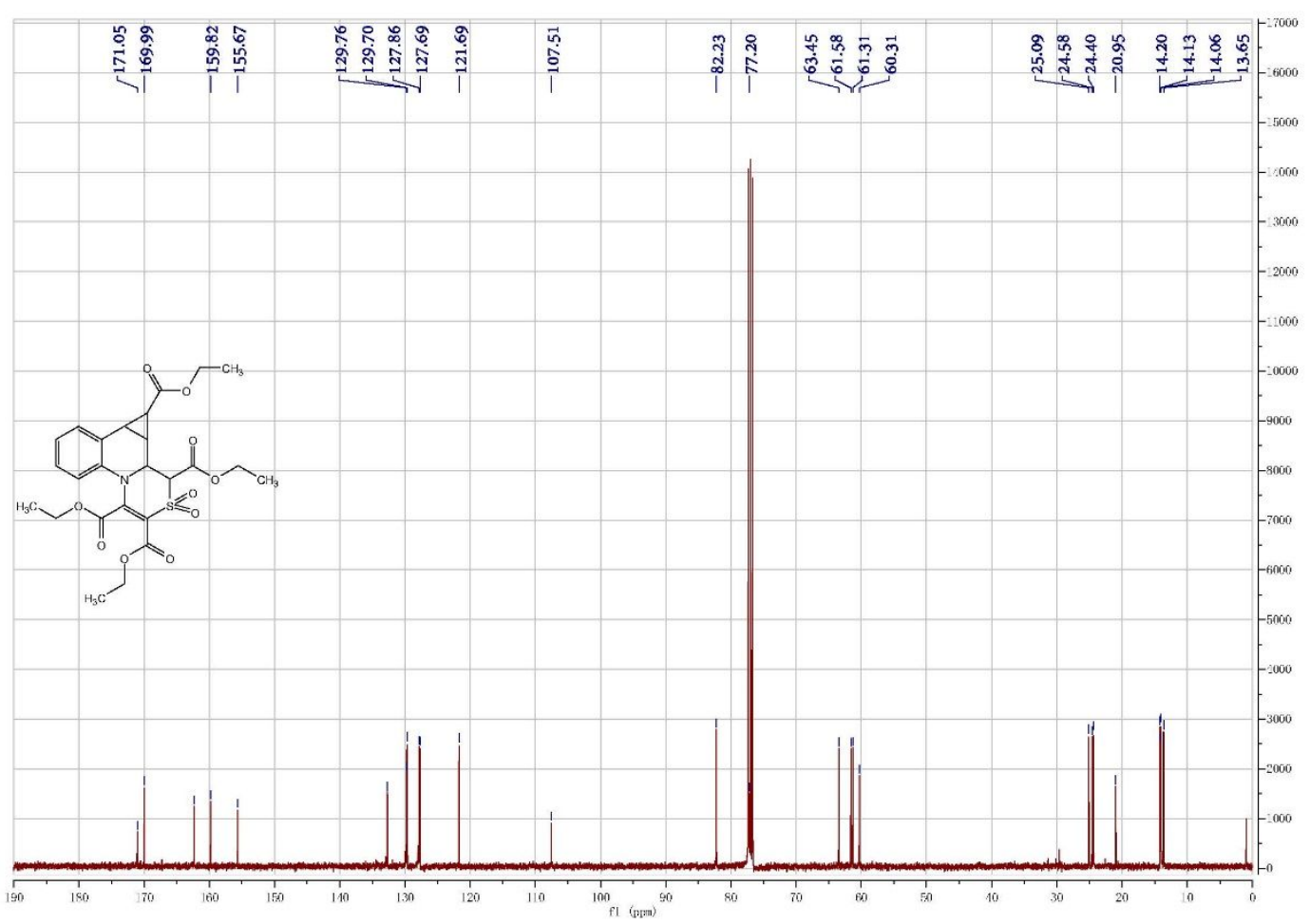

41 
${ }^{1} \mathrm{H}$ NMR (400 MHz, $\mathrm{CDCl}_{3}$ )

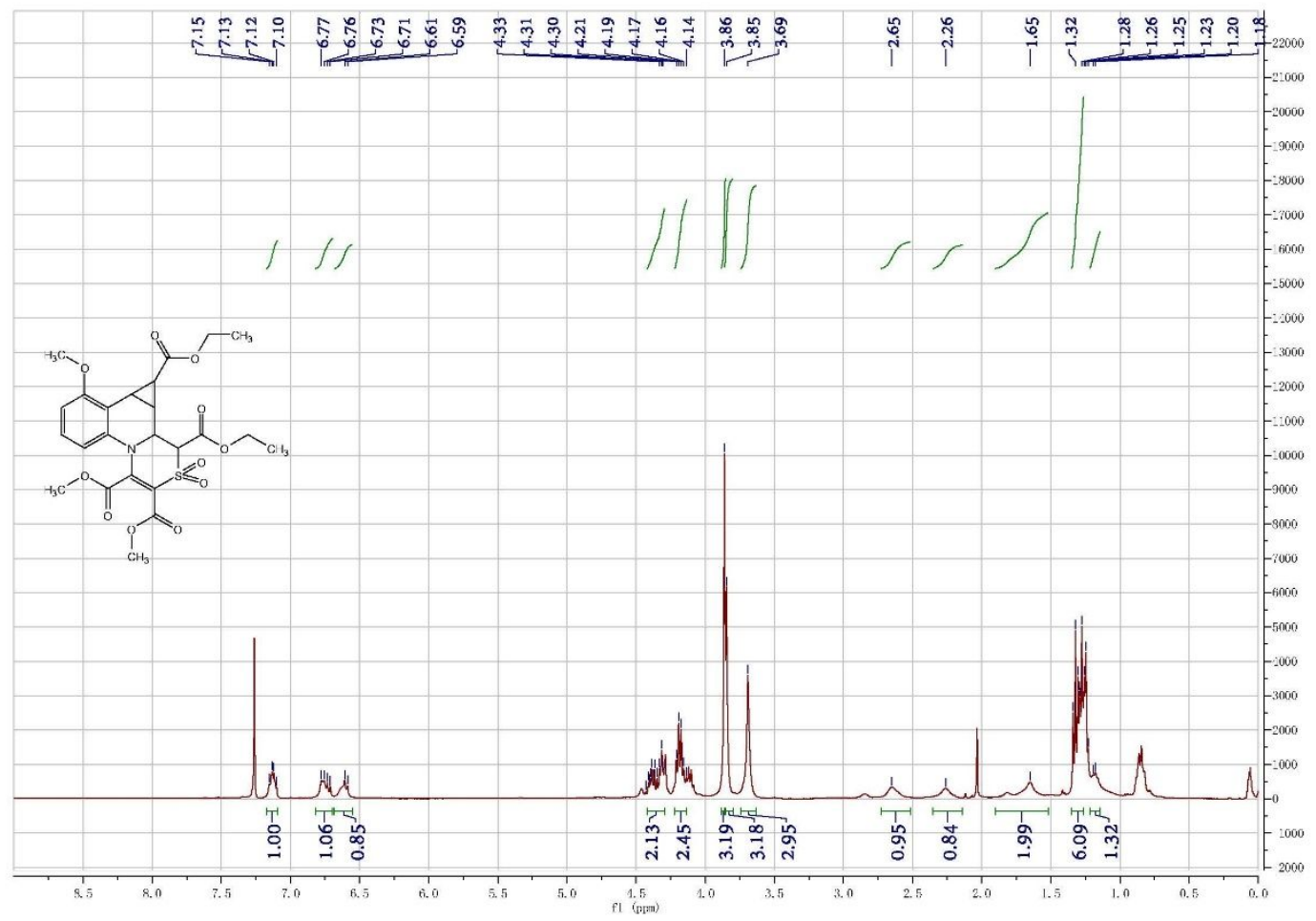

${ }^{13} \mathrm{C}\left\{{ }^{1} \mathrm{H}\right\}$ NMR $\left(100 \mathrm{MHz}, \mathrm{CDCl}_{3}\right)$

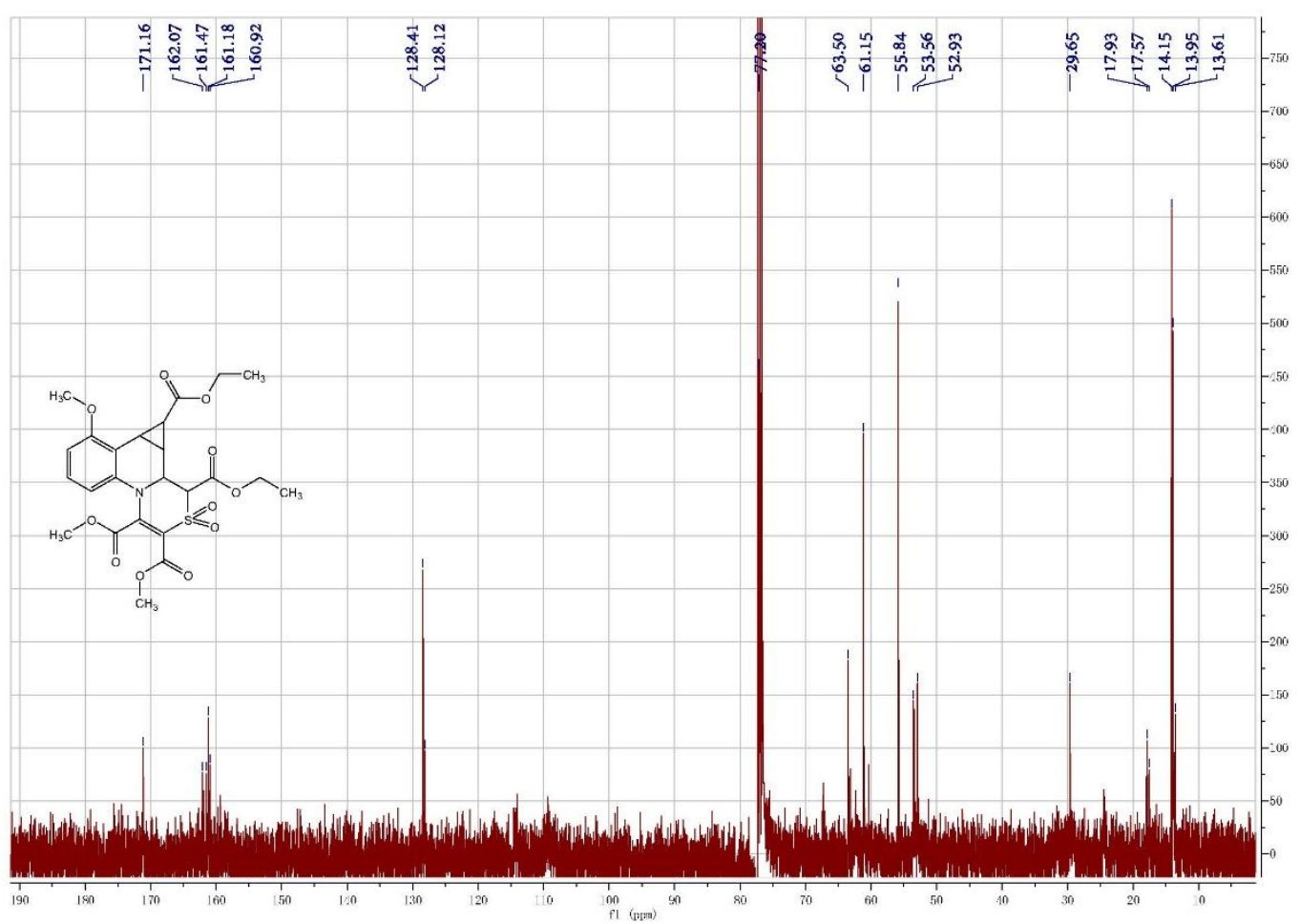

$4 I^{\prime}$ 
${ }^{1} \mathrm{H}$ NMR (400 MHz, $\mathrm{CDCl}_{3}$ )

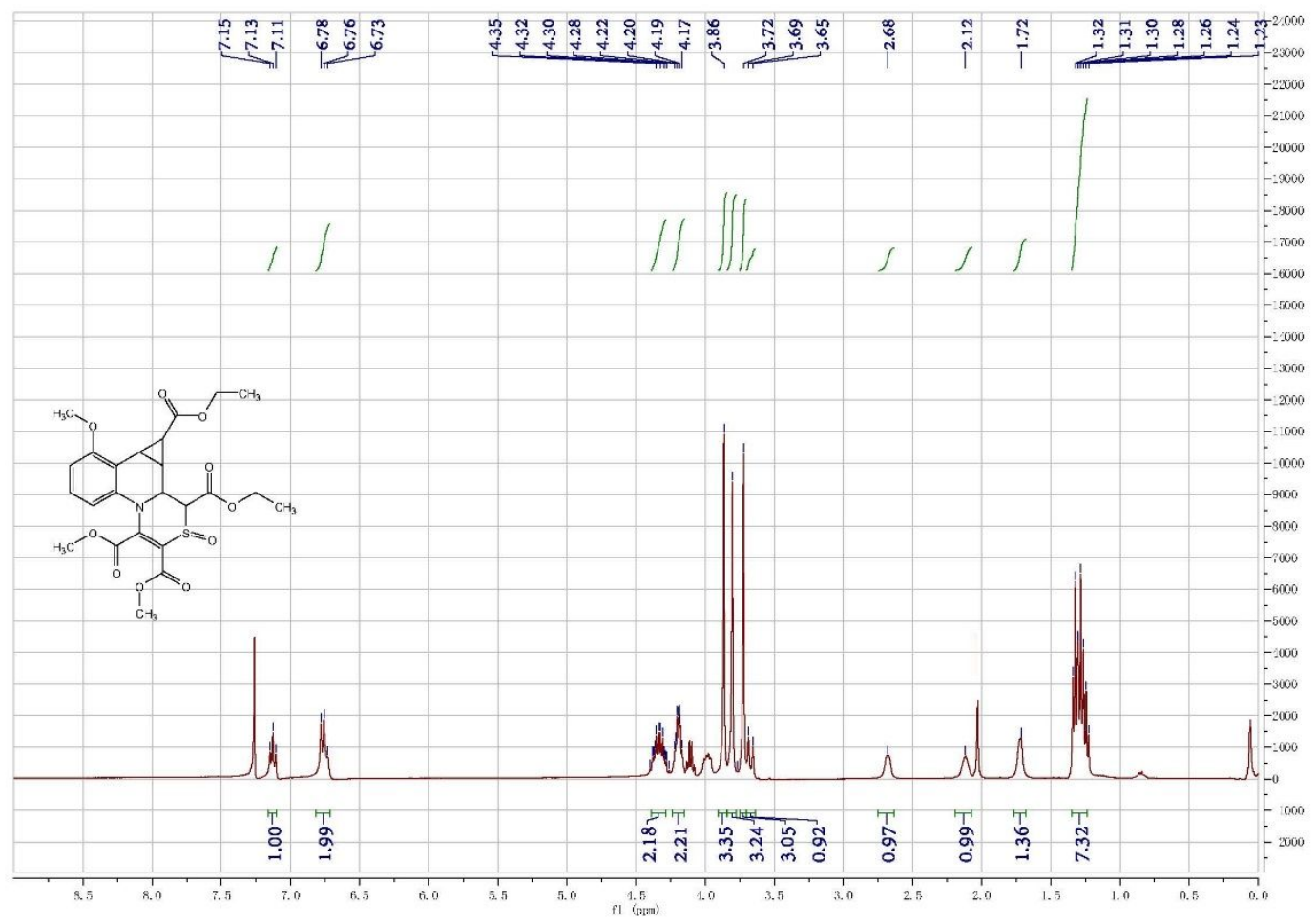

${ }^{13} \mathrm{C}\left\{{ }^{1} \mathrm{H}\right\}$ NMR $\left(100 \mathrm{MHz}, \mathrm{CDCl}_{3}\right)$

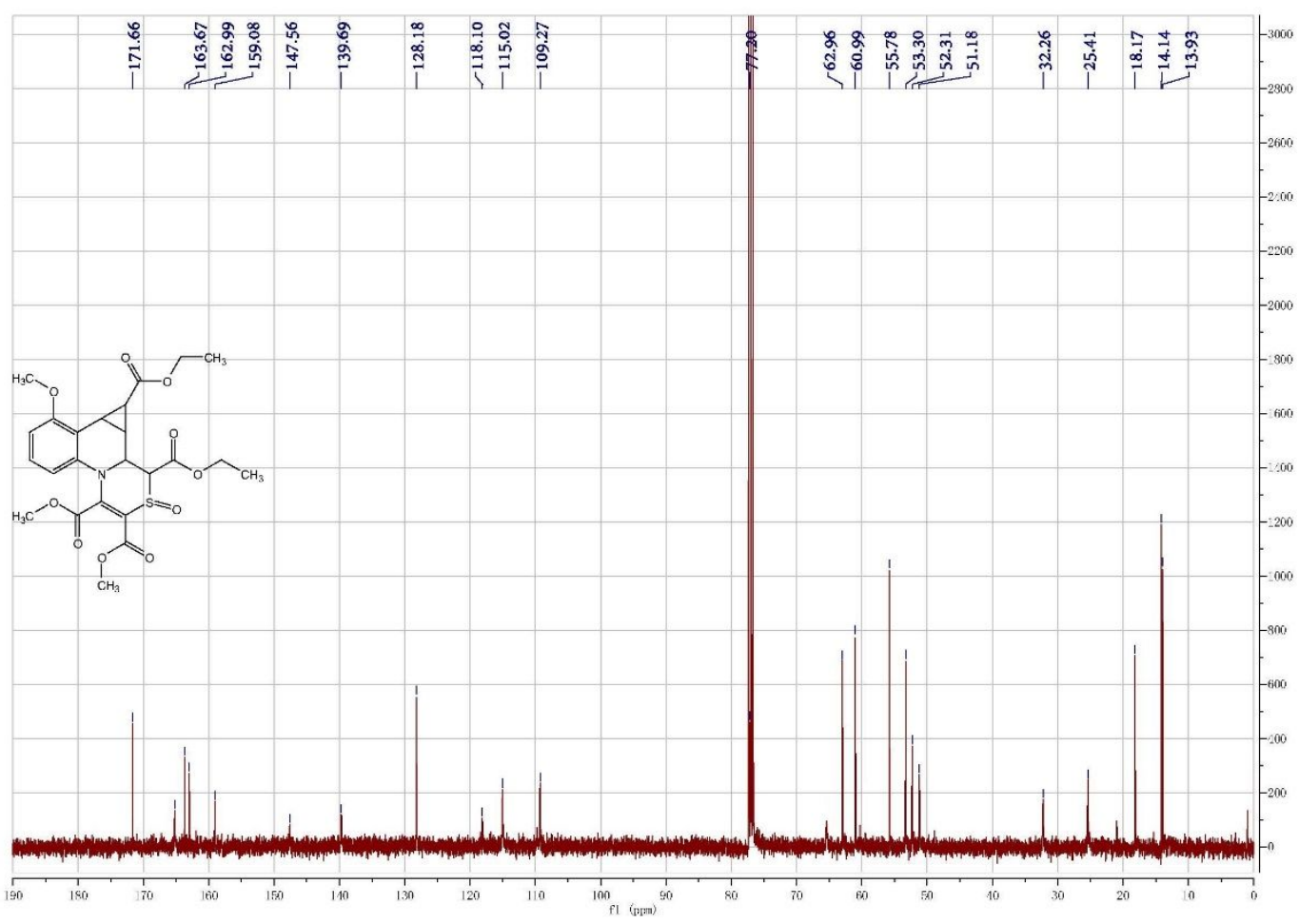

$4 m$ 
${ }^{1} \mathrm{H}$ NMR (400 MHz, $\mathrm{CDCl}_{3}$ )

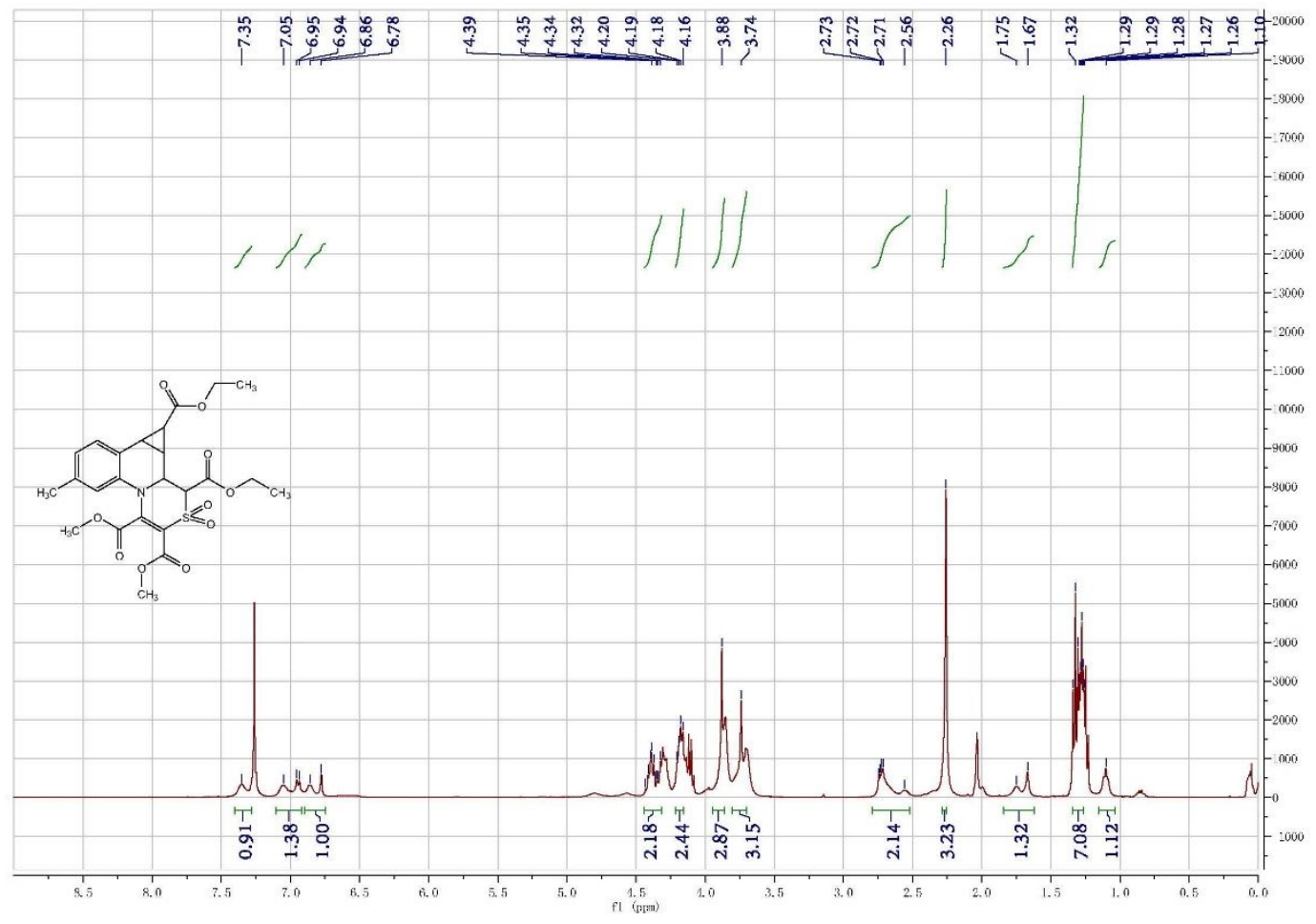

${ }^{13} \mathrm{C}\left\{{ }^{1} \mathrm{H}\right\}$ NMR $\left(100 \mathrm{MHz}, \mathrm{CDCl}_{3}\right)$

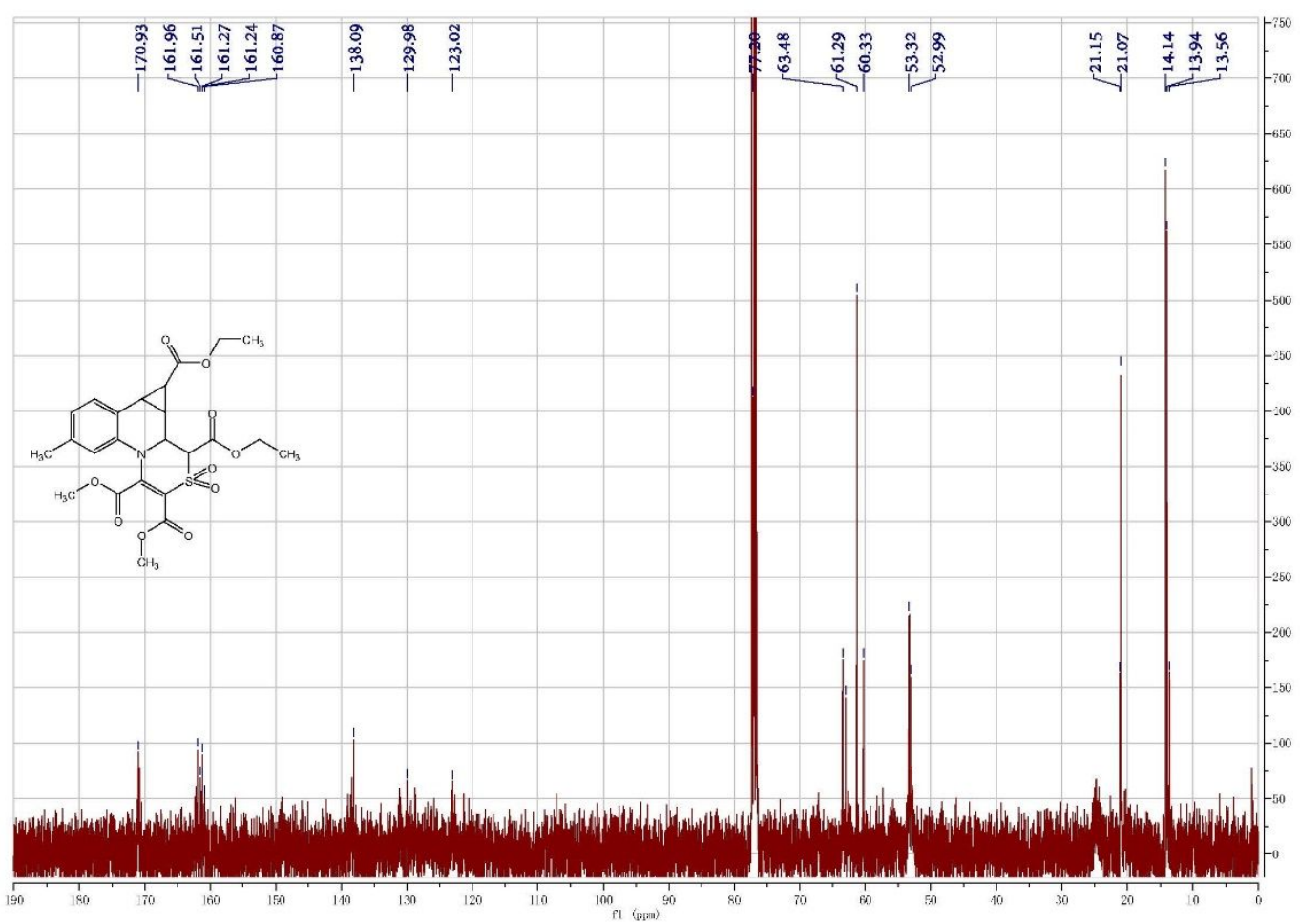

$4 m^{\prime}$ 
${ }^{1} \mathrm{H}$ NMR (400 MHz, $\mathrm{CDCl}_{3}$ )

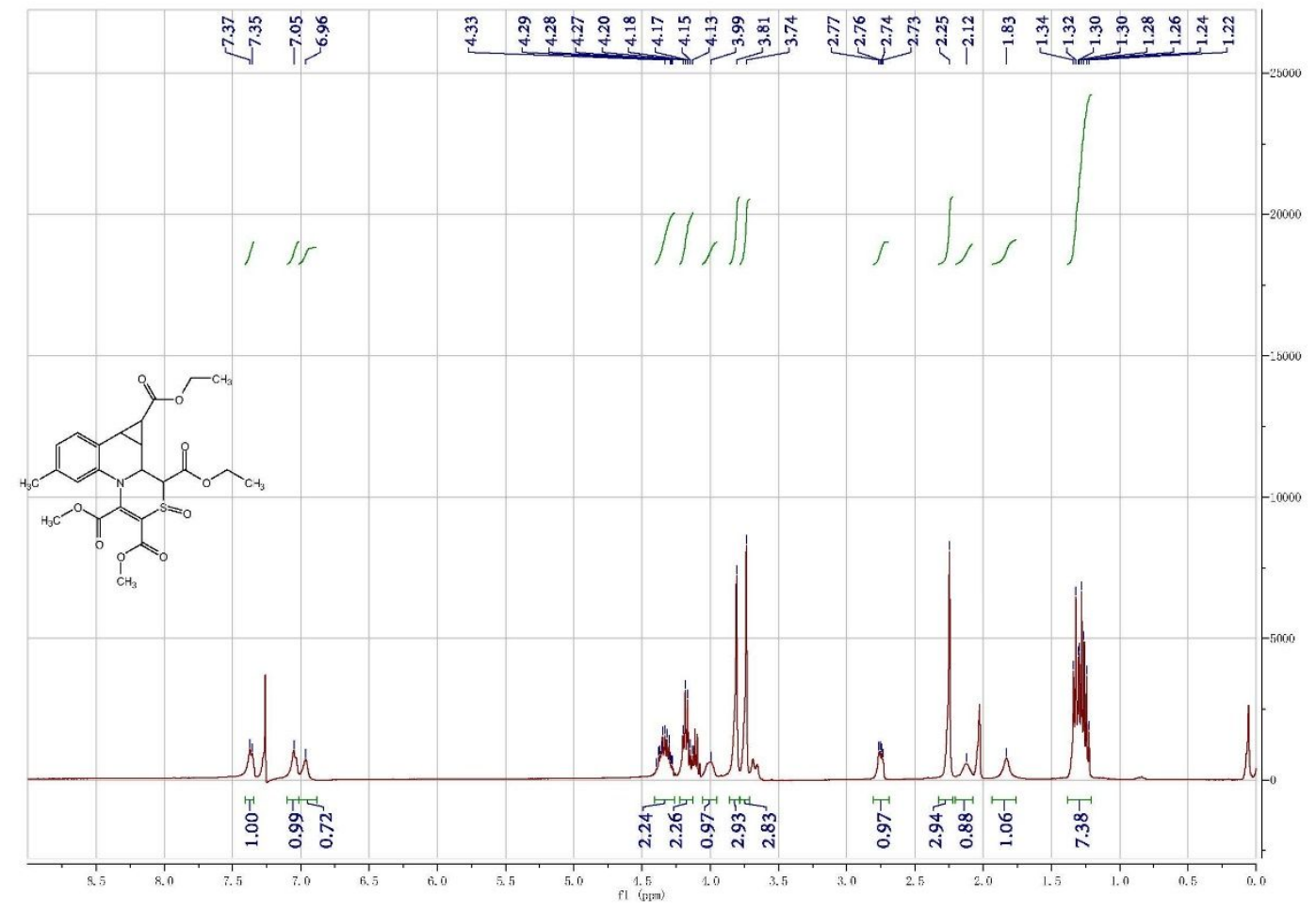

${ }^{13} \mathrm{C}\left\{{ }^{1} \mathrm{H}\right\}$ NMR $\left(100 \mathrm{MHz}, \mathrm{CDCl}_{3}\right)$

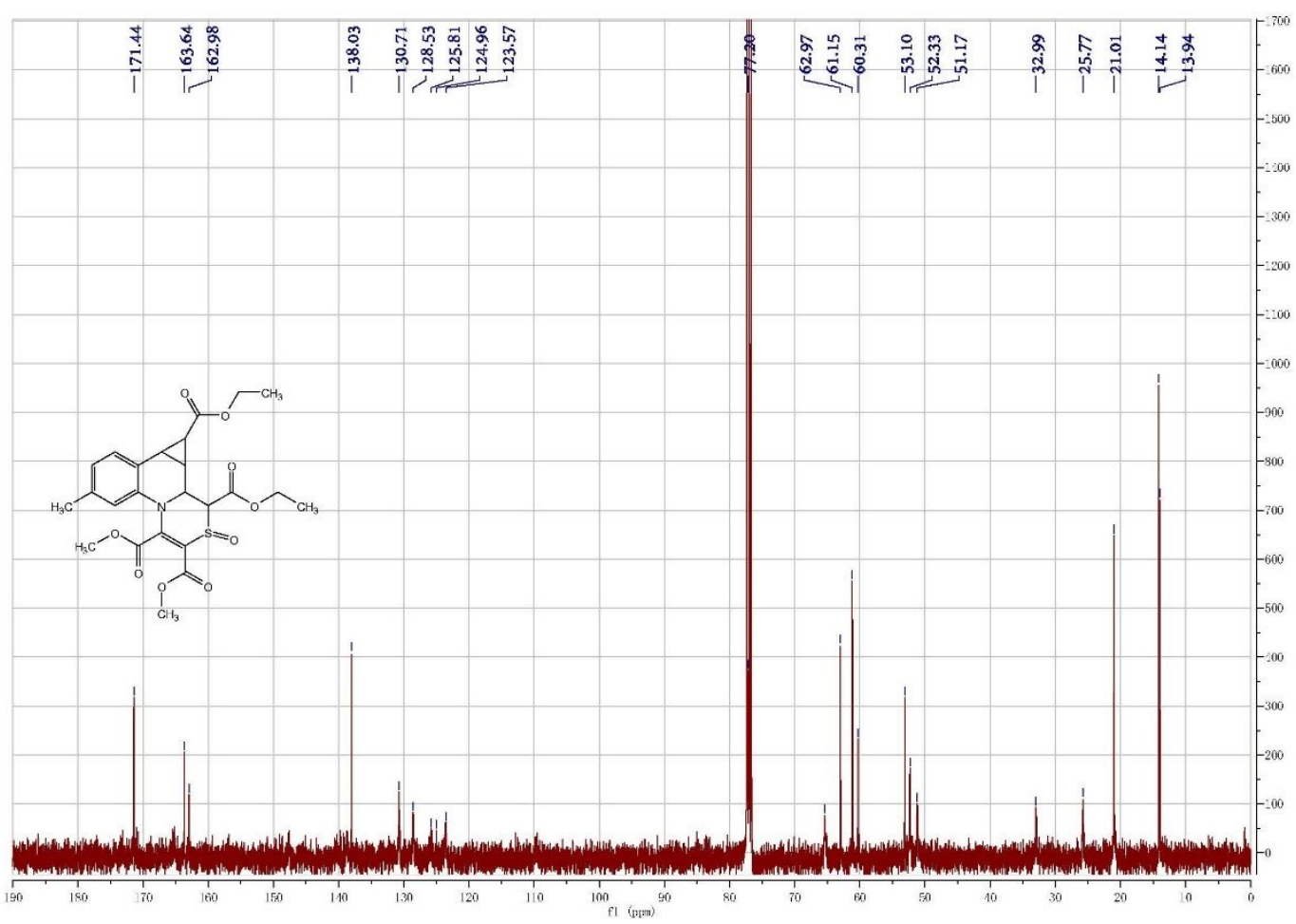

